\title{
Three-dimensional Structural Modeling (3D SM) and Joint Geophysical Characterization (JGC) of Hydrocarbon Reservoir: A Case Study of the Kadanwari field in Middle Indus Basin (MIB), Southeastern Pakistan
}

Umair Khan

Central South University

Jiangfeng Du

CNOOC Group: China National Offshore Oil Corp

Shafqat Hussain

Khyber Pakhtunkhwa Oil and Gas Co. Ltd.

Zhengwen Jiang

Central South University

Shahzad Ali

Khyber Pakhtunkhwa Oil and Gas Co. Ltd.

Ikram Ali

Khyber Pakhtunkhwa Oil and Gas Co. Ltd.

Majid Khan

University of Science and Technology Beijing

Baoyi Zhang ( $\nabla$ zhangbaoyi@csu.edu.cn )

Central South University https://orcid.org/0000-0001-6075-9359

\section{Research Article}

Keywords: 3D structural modeling (3D SM), 3D fault system models (FSMs), Seismic attribute models, Reservoir properties, Facies, Hydrocarbon-bearing zones

Posted Date: February 7th, 2022

DOl: https://doi.org/10.21203/rs.3.rs-1292168/v2

License: (c) (1) This work is licensed under a Creative Commons Attribution 4.0 International License.

Read Full License 
2 Three-dimensional Structural Modeling (3D SM) and Joint 3 Geophysical Characterization (JGC) of Hydrocarbon Reservoir: A Case Study of the Kadanwari field in Middle Indus Basin 5 (MIB), Southeastern Pakistan

6 Umair Khan ${ }^{1}$, Jiangfeng Du ${ }^{2}$, Shafqat Hussain ${ }^{3}$, Zhengwen Jiang ${ }^{1}$, Shahzad Ali ${ }^{3}$, Ikram Ali ${ }^{3}$, Majid Khan ${ }^{4}$, 7 Baoyi Zhang ${ }^{1, *}$

Citation: Lastname, F.; Lastname, F.; Lastname, F. Title. Appl. Sci. 2022, 12, x. https://doi.org/10.3390/xxxxx

Academic Editor: Firstname Lastname

\section{Received: date}

Accepted: date

Published: date

Publisher's Note: MDPI stays neutral with regard to jurisdictional claims in published maps and institutional affiliations.

Copyright: () 2022 by the authors. Submitted for possible open access publication under the terms and conditions of the Creative Commons Attribution (CC BY) license (https://creativecommons.org/license s/by/4.0/).

\author{
Key Laboratory of Metallogenic Prediction of Nonferrous Metals \& Geological Environment Monitoring \\ (Ministry of Education) / School of Geosciences \& Info-Physics, Central South University, Changsha 410083, \\ China; umair77@csu.edu.cn (U.K); jiangzhengwen@csu.edu.cn (Z.J) \\ 2 CNOOC Research Institute Co. Ltd., Beijing 100028, China; dujf@cnooc.com.cn(J.D.) \\ 3 Khyber Pakhtunkhwa Oil and Gas Co. Ltd. (KPOGCL), Pakistan; shafqat.dpc@kpogcl.com.pk (S.H); \\ shehzadali.dpc@kpogcl.com.pk (S.A); ikram.dpc@kpogcl.com.pk (I.A) \\ 4 School of Civil and Resource Engineering, University of Science and Technology Beijing, Beijing 100083, \\ China; majid@ustb.edu.cn (M.K) \\ * Correspondence: zhangbaoyi@csu.edu.cn
}

\begin{abstract}
Complex structural geology generally leads to significant consequences for hydrocarbon reservoir exploration that needs a comprehensive methodology for complete comprehension. Despite a large number of existing wells in the Kadanwari field, Middle Indus Basin (MIB), Pakistan, the depositional environment of the Early Cretaceous stratigraphic sequence is still poorly understood, which has implications for regional geology as well as economic significance. To improve the understanding of depositional environment of complex heterogeneous reservoirs with associated 3D stratigraphic architecture, spatial distribution of facies and properties, and hydrocarbon prospects, a new methodology of three-dimensional structural modeling (3D SM) and joint geophysical characterization (JGC) is introduced in this research. JGC makes use of seismic interpretation-aided 3D SM, 3D seismic attributes analysis coupled with quantitative petrophysical modeling using 3D seismic reflection and borehole data. Subsequently, the 3D SM reveals that the field experienced multiple stages of complex deformation dominated by NW to SW normal fault system, high relief horsts, half-graben, and graben structures. 3D SM and 3D fault system models (FSMs) further depict that the middle part of the sequence experienced more deformation compared to the surroundings of major faults with predominant oriented in $\mathrm{S} 30^{\circ}-45^{\circ} \mathrm{E}$ and $\mathrm{N} 25^{\circ}-35^{\circ} \mathrm{W}$, azimuth as $148^{\circ}-170^{\circ}$ and $318^{\circ}-345^{\circ}$, minimum $\left(28^{\circ}\right)$, mean $\left(62^{\circ}\right)$, and maximum $\left(90^{\circ}\right)$ dip angles. The applied variance edge attribute better portrays the inconsistency of the seismic data associated with faulting and estimated high reflection sediments presumed to be potential hydrocarbon traps. The high amplitude and loss of frequency anomalies of sweetness and root mean square (RMS) amplitude attributes represent payable sand-rich shoreward facies revealing gas saturated sand, while relatively low amplitude and high-frequency anomalies indicate sandy shale, shale, and pro-delta facies. The petrophysical modeling result shows that $\mathrm{E}$ sand interval has good effective porosity $\left(\emptyset_{\text {eff }}\right)$ and hydrocarbon saturation $\left(S_{\text {hc }}\right)$ compared to $G$ sand interval. The derived average petrophysical properties, such as volume of shale $\left(\mathrm{V}_{\text {shale }}\right)$,

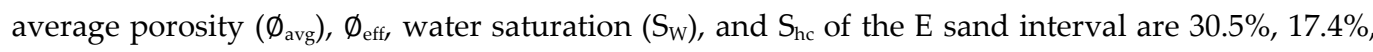
$12.2 \%, 33.2 \%, 70.01 \%$, respectively. The newly introduced 3D SM and JGC workflow is an effective tool for highlighting potential areas of high quality reservoir development.
\end{abstract}

Keywords: 3D structural modeling (3D SM); 3D fault system models (FSMs); seismic attribute models; reservoir properties; facies; hydrocarbon-bearing zones 


\section{Introduction}

The current inflation in fuel demand has increased hydrocarbon production from established reservoirs globally [1,2]. According to the United States Energy Information Administration (EIA), Pakistan may have over 9 billion barrels (1.4×109 cubic meters) of oil and 105 trillion cubic feet (3.0 trillion cubic meters) in natural gas (including shale gas) reserves [3,4]. Pakistan gas fields are only expected to last for about another 20 years at the most due to heavy industrial usage. Therefore, more characterization and re-evaluations of the already discovered petroleum systems are required to evaluate reservoirs prospects to meet the hydrocarbon requirements [2,4-7].

Reservoir characterization is a scheme that quantifies the physical and fluid properties of rock, such as lithology, volume of shale $\left(\mathrm{V}_{\text {shale }}\right)$, average porosity $\left(\emptyset_{\text {avg }}\right)$, effective porosity $\left(\emptyset_{\mathrm{eff}}\right)$, permeability $(\mathrm{K})$, water saturation $\left(\mathrm{S}_{\mathrm{W}}\right)$, and hydrocarbon saturation $\left(S_{h c}\right)$ [1,2,6,8-11]. It also includes understanding of reservoir structure, sedimentological heterogeneity, facies, and quantity of hydrocarbon that may exist in structural traps driven by tectonic movements, discontinuities like faults, folds anticlinal structures, horst and graben pop up geometries, and duplex structures [1,2,7,8,12-17]. The advancement in 3D seismic reflection surveys and borehole geophysics has made it possible to characterize structural and stratigraphic features and associated petrophysical properties with a high reliability and precision, thereby reducing the risk associated with hydrocarbon exploration $[9,18,19]$. Employing more than one tool to derive a consistent answer enables both precision and accuracy. Therefore, reservoir characterization (e.g., evaluation of structural and stratigraphic features, distribution of associated petrophysical properties and facies) can be better comprehended by employing integrated seismic interpretation-aided 3D structural modeling (3D SM), 3D seismic attribute analysis, and petrophysical modeling [2,9,13,20-24]. 3D SM is divided into the entity-based modelling and volume-based modelling (VBM) [25-30]. The former expresses the 3D structural models using the combination of four different geometric entities, i.e., point, line, surface and body, and emphasizes the shape of geological structures and the relationship among geological bodies. The latter subdivides the 3D space into discrete fields by regular or irregular voxels and emphasizes the spatial distribution of geophysical and geochemical properties. The advantages of 3D seismic exploration include better stratigraphic information, true structural dip, better areal mapping of faults, and better lateral resolution [31]. The development of accurate 3D reservoir geological structure models using 3D seismic data is essential for reservoir description, e.g., predicting hydrocarbon reserves, up-dip hydrocarbon migration pathways, and quantitative geometric characterization in 3D space. With the continuous development of reservoir geological modeling technology, the VBM, objective function, variation function, multipoint geostatistics, static geological modeling with knowledge-driven methodology, and other mathematical methods have been widely applied in reservoir modeling, which significantly promoted the development and technology of 3D reservoir geological modeling [32-36]. However, VBM is a step-change reservoir geological modeling technique that creates horizons based on depositional sequence instead of considering horizons as discrete surfaces $[2,12,37]$. This technique directly models volume using a discretized and heterogeneous tetrahedral mesh encompassing the fault framework.

Complex fault systems are difficult to identify using traditional seismic migration profiles. On the one hand, reservoir facies discrimination can be obtained from the laboratory studies on core plugs, which are costly and time-consuming. However, seismic attributes allow stratigraphic-based basin depiction within a composite deposition-based structure and discriminate sand facies from shale, thereby increasing the rate for adequate reservoir characterization $[38,39]$. Seismic attributes such as dip magnitude, edge enhancement, variance edge, sweetness, and root mean square (RMS) amplitude are essential tools for delineating structural and stratigraphic characteristics, lithofacies changes, and hydrocarbon potential zones [20,38,40,41][20,38,40,41]. On the 
other hand, petrophysical modeling plays an essential role in reservoir characterization, especially in discriminating the non-hydrocarbon and hydrocarbon-bearing intervals $[17,22,42,43]$. Due to the depth measure error, observation and analysis of the core samples taken from the subsurface formations have several limitations in reservoir properties assessment. However, logging gives a practically continuous survey of the formation properties and makes it possible to determine the reservoir properties based on various logging curves. Proper analysis of reservoir lithology, $V_{\text {shale, }} \emptyset_{\text {avg, }} \emptyset_{\text {eff, }} S_{W}$, and $S_{h c}$ can significantly improve the ability to distinguish non-hydrocarbon and hydrocarbon-bearing zones.

The Middle Indus Basin (MIB) and Lower Indus Basin (LIB) are well known for hydrocarbon exploration in Pakistan [42]. The Kadanwari field in MIB is a significant hydrocarbon producing field with early-late Cretaceous Lower Goru formation (LGF) acting as the potential reservoir. Many researchers used different techniques on distinct parts of reservoir characteristics of most promising hydrocarbon formations in Pakistan and primarily focused on the MIB and LIB $[6,7,20,22,40,42-51]$. The regional subsurface structural style, such as orientation, geometry, and development of the fault system of the Miano and Kadanwari fields in MIB, was evaluated by Saif-Ur-Rehman et al. [7]. However, the study conducted by [20] and [40] validated the application of seismic attribute analysis to delineate the lateral and vertical facies distribution and their paleo-environments of LGF in the Sawan gas field, MIB. The stratigraphic pinch-out traps within the lower-cretaceous shaly-sandstone system in MIB were evaluated by [51] using 3D quantitative seismic inverted porosity and velocity modeling. Moreover, $[6,22,42,43,47,50]$ used petrophysical modeling based on geophysical logs to understand the reservoir properties and hydrocarbon potential. The systematic review of prospective observational studies found that the Kadanwari field in MIB has not received emerging conclusions for understanding the complex depositional environment using integrated approach (e.g., joint representation and parameterization of 3D geological structural, seismic attributes, and petrophysical characteristics). It provides a missing link to evaluate the complex depositional environments along with 3D stratigraphic architecture, lateral and horizontal structural extent of the reservoirs, faults geometry and orientation, spatial facies, and key reservoir properties using 3D structural modeling (3D SM) and joint geophysical characterization (JGC).

In addition, structural and stratigraphic characteristics and associated tectonic extensional FSMs are essential aspects in sustaining the migration pathway for hydrocarbons in the Kadanwari field, MIB, and elsewhere in the world [46]. Meanwhile, it is challenging to predict the distribution of key petrophysical properties and facies in the Kadanwari field due to fluctuating deltaic conditions, mutable geological influences, varying mineralogical concentrations, regional tectonic settings, and changes in geometries. This study, therefore, utilized 3D SM and JGC that comprises seismic interpretation-aided 3D SM, 3D seismic attribute analysis, and petrophysical modeling using 3D seismic and wells logs data. 3D SM and JGC conceived innovative contributions and created a more explicit representation of the complex and heterogeneous depositional environments with associated 3D stratigraphic architecture, lateral and horizontal structural extent of reservoir horizons, FSMs (including faults geometry and orientation in 3D space), spatial facies, reservoir properties (e.g., lithology, $\mathrm{V}_{\text {shale, }} \emptyset_{\text {avg, }} \emptyset_{\text {eff, }} S_{\mathrm{W}}$, and $S_{\text {hc }}$, and direct hydrocarbon indicators (DHIs). Indeed, such in-depth studies are essential to characterize and evaluate reservoir geometrical characteristics and properties to reduce uncertainties and improve the success rate of future exploration and development plans for hydrocarbons in the study area, and potentially applicable to other regions in the world.

\section{Background Geology}

Pakistan is located at the triple junction of the Indian, Eurasian and Arabian plates (Figure 1a). The Tertiary plate convergence between the Indian and Eurasian continents 
affected the north and northwestern sides of Pakistan. The convergence of the Arabian oceanic plate with the Afghan craton in the south and southwestern part of Pakistan resulted in many structural regimes [48,52]. During the middle/late Jurassic to early Cretaceous, the Indian plate rifted away from the Gondwana land, forming an island continent that drifted northwards into the Tethyan Ocean [52]. This tectonic event predominantly controlled the structures and sedimentation of the MIB and LIB, which possibly resulted in NE-SW to N-S rift systems. The Kadanwari field is located in the District Khairpur of Sindh Province, southeast MIB, a prolific gas-prone basin of Pakistan (Figure $1 \mathrm{~b}$ ). The latitude of the study area ranges from $27^{\circ} 04^{\prime} 83^{\prime \prime} \mathrm{N}$ to $27^{\circ} 07^{\prime}$ $12^{\prime \prime} \mathrm{N}$, and longitude varies from $69^{\circ} 12^{\prime} 98^{\prime \prime} \mathrm{E}$ to $69^{\circ} 17^{\prime} 57^{\prime \prime} \mathrm{E}$. Tectonically, the Kadanwari field lies between two extensive regional highs, i.e., the Mari-Kandhkot High and Jacobabad-Khairpur High (Figure 1c). In the east, it is bounded by Indian shield; the Sargodha high in the north; fold and thrust belt of the Kirthar and Sulaiman Ranges in the west and the south by the Jacobabad-Khairpur High [7,45,49,52].

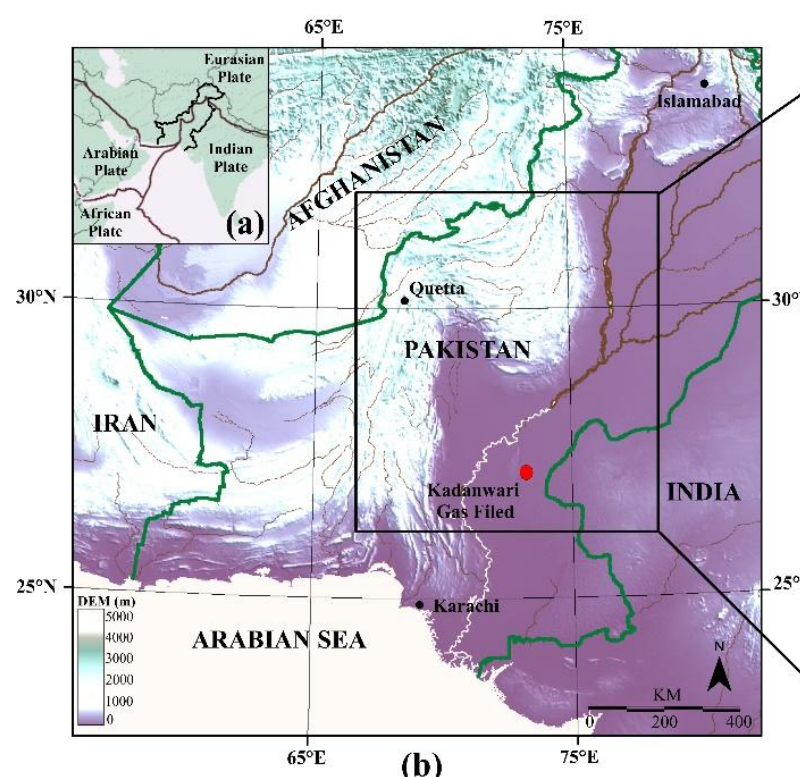

(b)

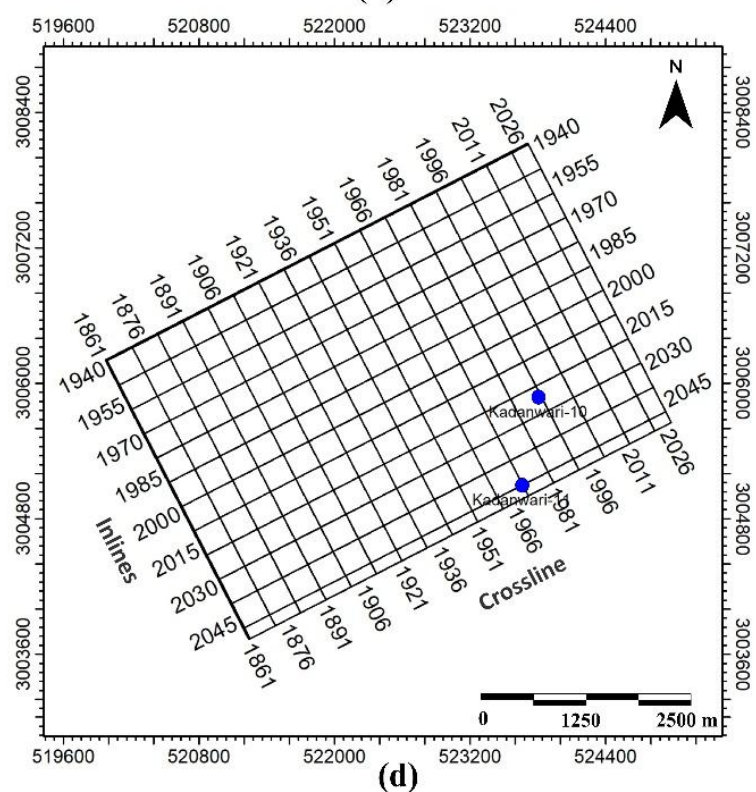

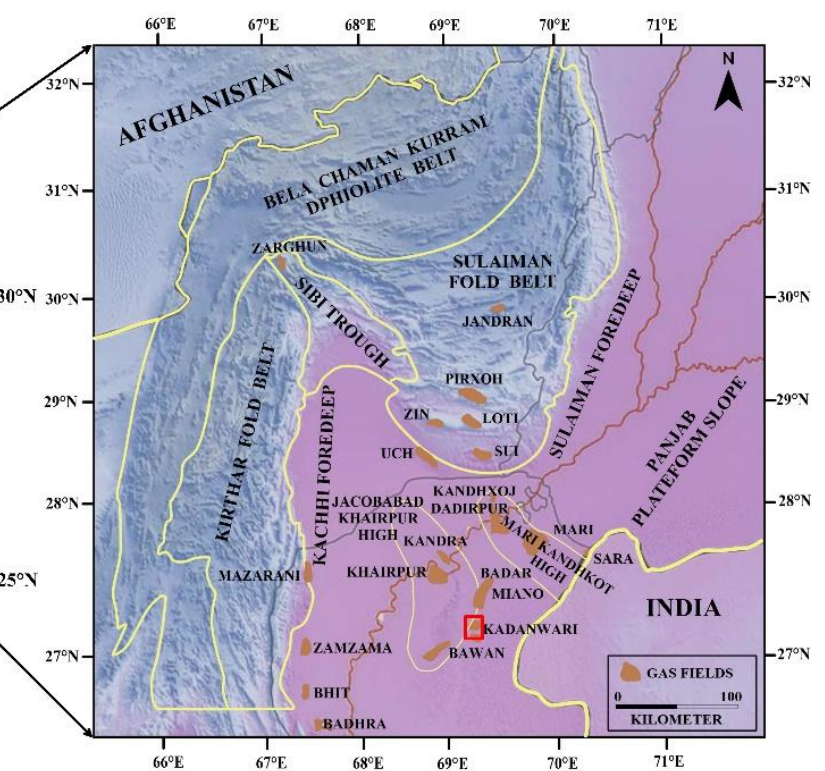

(c)

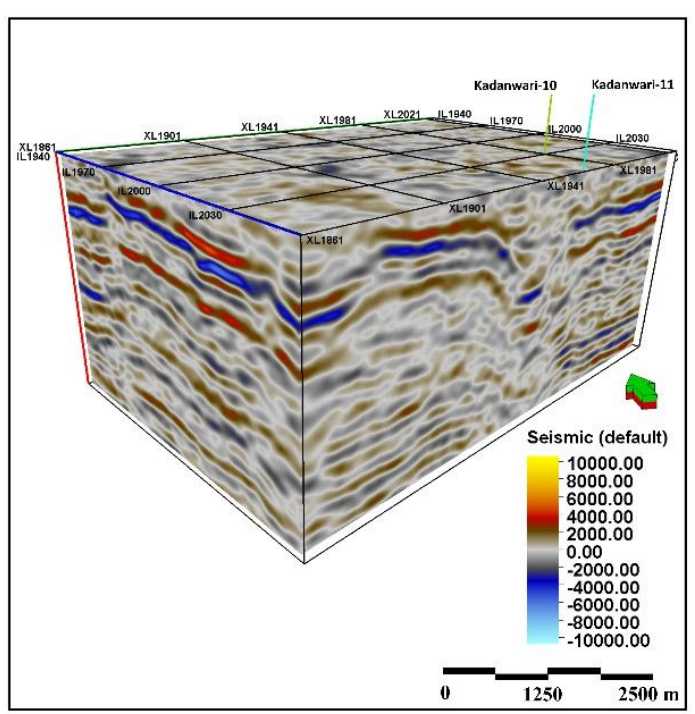

(e)

Figure 1. (a) Pakistan location at the triple junction of the Indian, Eurasian and Arabian plates; (b) Location of the study area; (c) Generalized tectonic map with the location of major oil and gas producing fields in the study area bounded by other gas fields, modified after [48]; (d) 2D and; (e) 
3D base map shows the orientation and information of 3D seismic lines and wells in the Kadanwari field, MIB, Pakistan

Three tectonic events were responsible for the structural configuration in the study area, namely, the late Cretaceous uplift and erosion, the late Paleocene wrench faulting, and the late Tertiary to Quaternary uplift/inversion of Jacobabad High (Figure 1c) [52]. The Jacobabad-Khairpur High was an essential contributor to structural traps in the study area and surroundings $[45,49]$. The final tectonic event of the late Tertiary to Quaternary was an inversion of the Jacobabad-Khairpur High, which significantly influenced the Kadanwari area [45,52]. In the Kadanwari field and surroundings, the trapping mechanism is a complex combination of structural dip, sealing faults, and loss of reservoir quality to the north. The Kadanwari field consists of several low relief faults, forming dip closures in the subsurface, providing a stratigraphic trapping component $[7,45]$. The faults dip closures and the wrench faults are particularly significant since they divided the Kadanwari field into reservoir compartments [42].

The lithology stack of MIB is depicted in Figure 2a, which highlights the basin fill sedimentary deposits. The lithostratigraphic columns show the rock units encountered in Kadanwari-10 and Kadanwari-11 wells (Figure 2b). According to [46], shales of the Sember Formation serve as a source rock for the regionally developed petroleum systems of the MIB. However, the reservoir section at the Kadanwari field belongs to the lower Goru sand (the Cretaceous age), while the sealing is provided with the upper Goru shaly sequence [50].

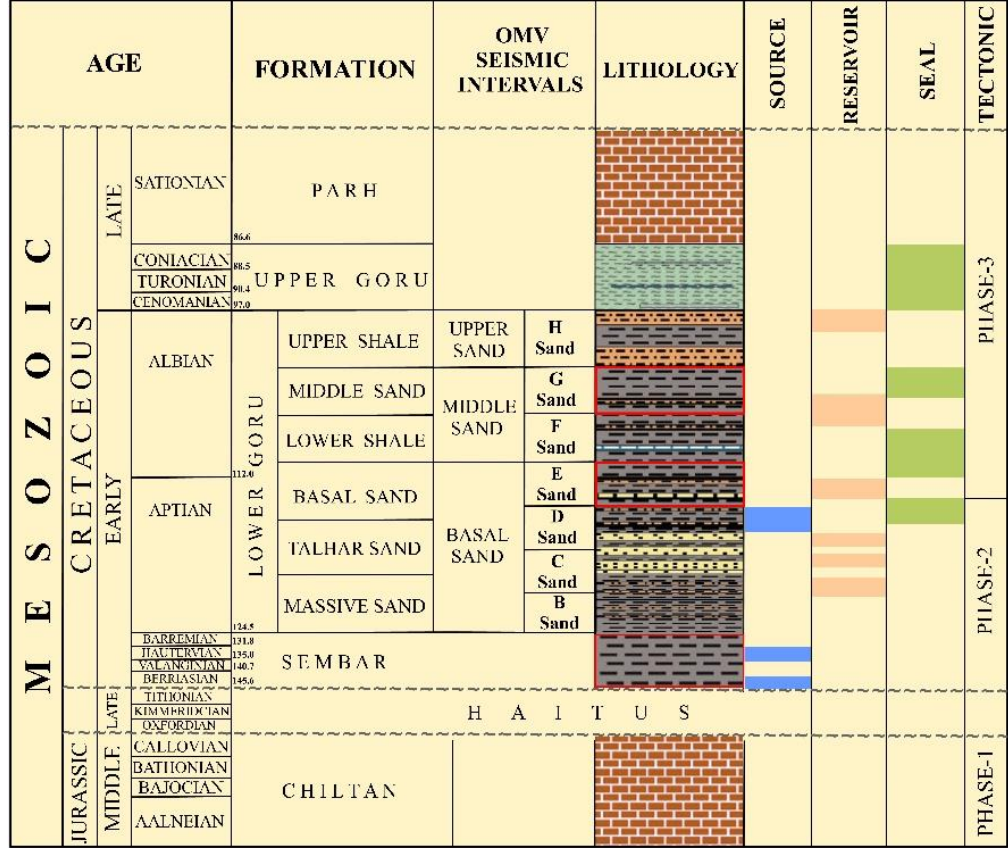

(a)

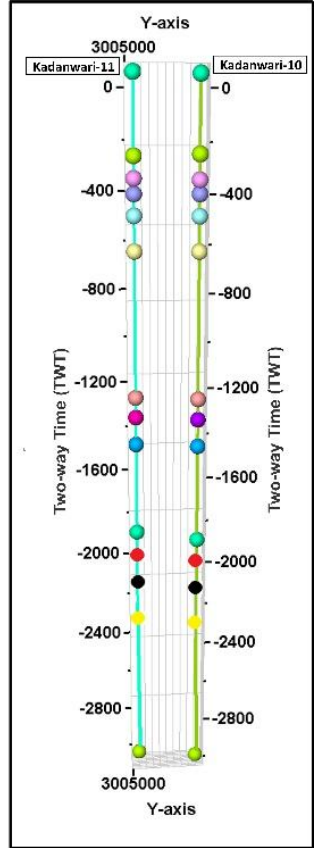

(b) 
A large volume of seismic reflection data was acquired in the MIB Pakistan to execute hydrocarbon exploration activities at different times, from 1970s to recently [7]. The OMV (www.omv.com), Austria's largest industrial company Pakistan branch, recently brought the Kadanwari field into a new exploration phase by conducting a 3D seismic survey. Instead of showing the subsurface beneath a profile line, 3D seismic displays more structural geological information, more complete view of reservoir properties, more realistic structural dip, better areal mapping of faults system, and higher lateral resolution [31]. The seismic data used in this study are post-stack time migrated seismic reflection cube stored in the SEG-Y format, wherein approximately 116 seismic inlines and approximately 181 cross-lines were used. The well logs data were provided in digital Log ASCII Standard (LAS files) and notepad file formats. The geometric information of the available 3D seismic data is presented in Tables 1 and 2, while the key information of well logs suites is summarized in Tables 3 and 4 . The available 3D seismic data and well logs data were collected from Landmark Resources (LMKR) (www.lmkr.com) upon the request of the Directorate General of Petroleum Concessions (DGPC) Pakistan (www.mpnr.gov.pk), which are available to the public domain and can be utilized for scientific and research purposes.

Table 1. Geometric information of the available 3D seismic data.

\begin{tabular}{cc}
\hline Geometric Properties & Values \\
\hline Total coverage area & $12 \mathrm{~km}^{2}$ \\
Coordinate reference system & UTM42PK \\
Inline interval & 24.17 \\
Crossline interval & 25.17 \\
Time slice range & -1800 to $-2600(\mathrm{~ms})$ \\
Sample interval & 5 \\
Number of samples per trace & 74 \\
\hline
\end{tabular}

Table 2. 3D seismic cube lines in the study area.

\begin{tabular}{cccc}
\hline Axis & Minimum & Maximum & Delta \\
\hline Latitude & $27^{\circ} 09^{\prime} 25.56^{\prime \prime}$ & $27^{\circ} 11^{\prime} 55.68^{\prime \prime}$ & $0^{\circ} 02^{\prime} 30.12^{\prime \prime}$ \\
Longitude & $69^{\circ} 12^{\prime} 0.56^{\prime \prime}$ & $69^{\circ} 15^{\prime} 16.22^{\prime \prime}$ & $0^{\circ} 03^{\prime} 15.36^{\prime \prime}$ \\
Trace & -6000.00 & 0.00 & 6000.00 \\
Seismic (template) & -10691.53 & 10608.00 & 21299.53 \\
Amplitude (data) & -10691.53 & 10608.00 & 21299.53 \\
\hline
\end{tabular}

Table 3. Utilized wells in the study area.

\begin{tabular}{ccccccc}
\hline Wells No. & Latitude & Longitude & Total Depth $(\mathbf{m})$ & Status & Formation Top & Depth Reference \\
\hline Kadanwari-10 & 27.172879 & 69.141227 & 3545 & Gas & Lower Goru & Kelly Bushing (KB) \\
Kadanwari-11 & 27.049794 & 69.173086 & 3534 & Gas & Lower Goru & Kelly Bushing (KB) \\
\hline
\end{tabular}

Table 4. Metadata of the utilized wireline logs and their uses in this study.

\begin{tabular}{cccc}
\hline Wireline Logs & Measured property & Petrophysical properties estimated & Product \\
\hline Caliper & Diameter & Borehole structure with depth & CALI \\
Gamma-ray & Radioactivity & Shale volume (V Vhale & GR \\
Laterolog deep & Resistance to electric current & Uninvaded resistivity & LLD \\
Laterolog shallow & Resistance to electric current & Invaded zone resistivity & LLS \\
Micro-spherical focused log & Resistance to electric current & Mud cake resistivity & MSFL \\
Sonic & Velocity of sound waves & Porosity & DT \\
Spontaneous Potential & Electric potential & Formation water resistivity & SP \\
\hline
\end{tabular}




\begin{tabular}{cccc}
\hline Neutron & Hydrogen concentration & Porosity & NPHI \\
Density & Bulk density & Porosity & RHOB \\
\hline
\end{tabular}

Before proceeding with seismic data analysis, it was essential to match the coordinate systems provided in the well report to the coordinate reference system (CRS). Consequently, the available 3D seismic cube in SEG-Y format and wireline log data were integrated for 3D SM and 3D seismic attribute analysis. The dataset quality was first checked and harmonized in a clearly defined database. Accordingly, a base map located in the 42-N Trans-Mercator Macrocosm (UTM) zone was created by using navigation and SEG-Y records to check for the orientation and information (dip or strike) of seismic lines and well locations (Figure 1d).

\subsection{Joint Geophysical Characterization (JGC)}

JGC requires a number of iterations for getting better constrained on the reservoir characteristics. In this paper, JGC makes use of an integrated 3D SM approach involving structurally constrained geological models along with seismic attribute implications and petrophysical properties that significantly enhance the understanding of the reservoir characteristics leading to reliable reservoir assessment. Figure 3 shows the complete applied workflow for the present case study. Firstly, seismic and well logs data were utilized, and interpretation was carried out, which involves synthetic seismograms generation, extracting and interpreting specific stratigraphic interface (geological period) and faults as geometric features in 2D cross-sectional (i.e., vertical) slices of a 3D seismic volume. Secondly, seismic reflection discontinuity was reviewed for accuracy using dip magnitude and edge enhancement attributes; meanwhile, 3D FSMs and their attribute models such as dip angle, faults rose diagram, and histogram was constructed to evaluate the fault mechanics and geometric distribution. Thirdly, 3D SMs of the early Cretaceous stratigraphic sequence were constructed by the VBM algorithm, which incorporates all geometry definitions (e.g., constraints from well tops, geologic horizons, and FSMs). Fourthly, several seismic attributes such as variance edge, sweetness, and RMS amplitude were applied to 3D seismic data, which involves extracting corresponding qualitative and quantitative geological features to validate the interpreted spatial forecasts of the geological structure and evaluate lithofacies distribution and potential hydrocarbon zones. Finally, petrophysical modeling based on various wireline logs (CALI, GR, SP, LLD, LLS, MSFL, DT, NPHI, and RHOB, explained in Table 4) were performed to estimate reservoir properties (e.g., lithology, $V_{\text {shale, }} \emptyset_{\text {avg, }} \emptyset_{\text {eff, }}$ $S_{\mathrm{W}}$, and $\left.S_{\mathrm{hc}}\right)$. 


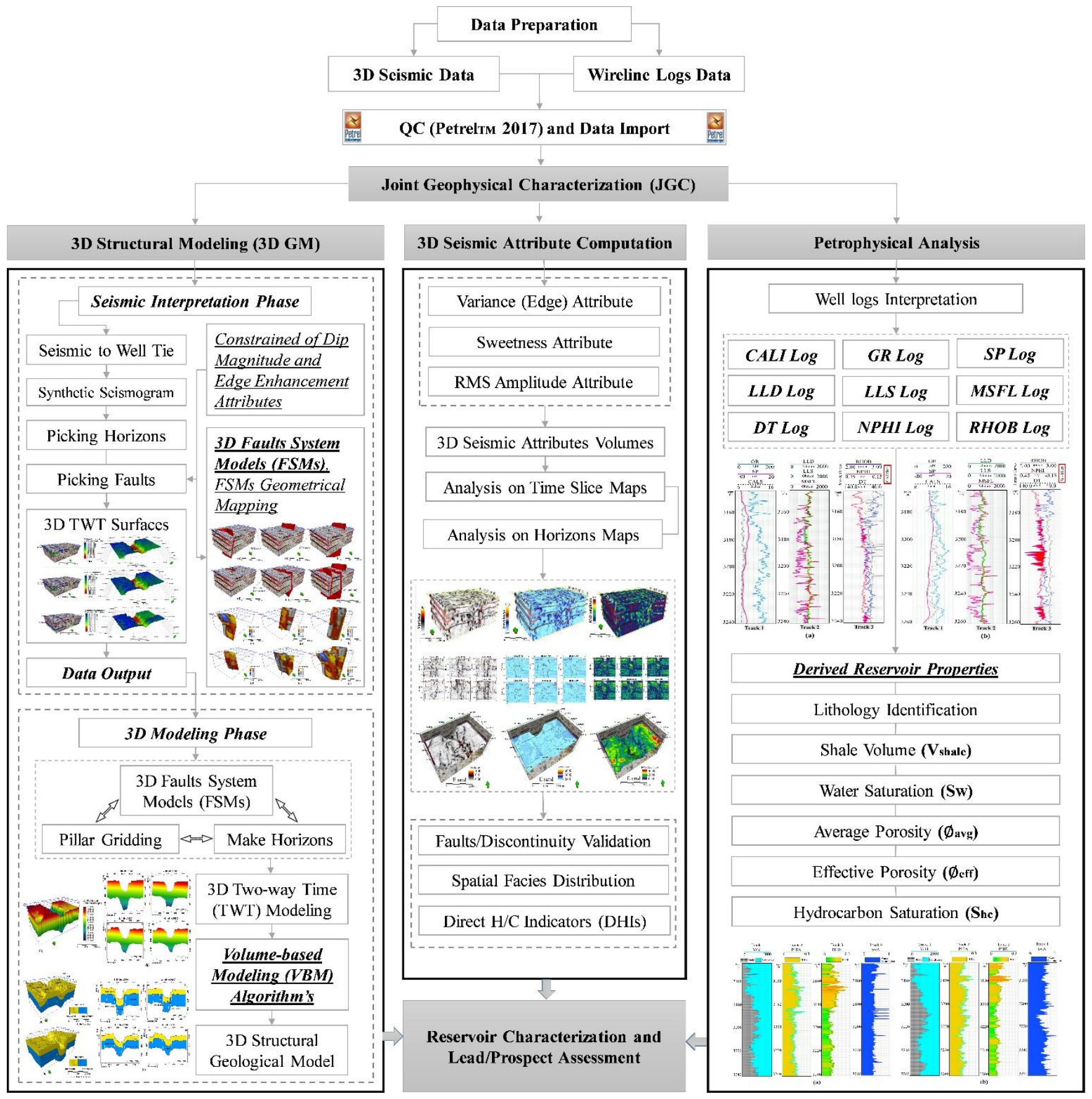

Figure 3. Workflow highlighting various steps and methods employed in this study for reservoir characterization and lead/prospect assessment of the Kadanwari field, MIB, Pakistan.

\subsubsection{Seismic Data Analysis}

A brief summary of the available 3D seismic data and wireline logs data are presented in Table 1-4. The available 3D seismic data and wireline logs were analyzed using conventional seismic interpretation to simulate specific stratigraphic interfaces of Early Cretaceous stratigraphic sequence, e.g., G sand interval, E sand interval, and the Sembar Formation in the Kadanwari field, MIB. Seismic interpretation was performed primarily in two phases, including interpretation and modeling.

The interpretation step of seismic data analysis involves coordinate conversion, well to seismic tie using synthetic seismogram, picking stratigraphic interface, and interpreting fault system $[19,23,53]$. The complete workflow of seismic to well tie 


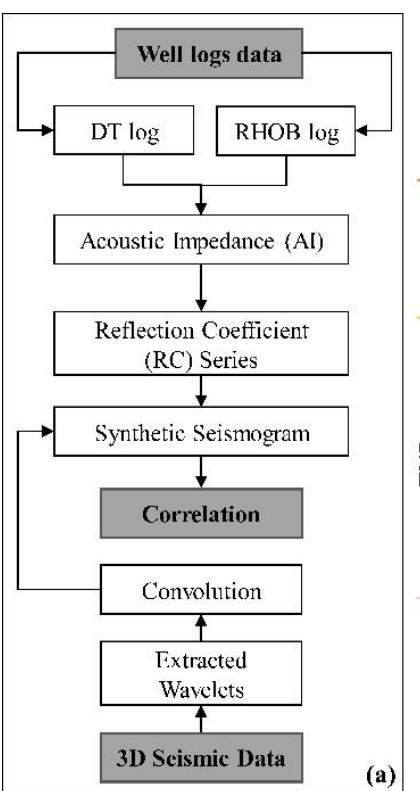

analysis is presented in Figure 4a, where seismic amplitude was correlated with wireline logs in order to identify and interpret key horizons on $2 \mathrm{D}$ cross-sectional (i.e., vertical) slices of a 3D seismic volume. Accordingly, velocity data from the DT log together with the RHOB log were used to generate acoustic impedance (AI) and then reflection coefficient (RC) series (Equation 1). The RC series were convolved with seismic wavelets to create a synthetic seismogram. The synthetic seismogram and surface seismic correlation are presented in Figure $4 \mathrm{~b}$, where stratigraphic interfaces (horizons) were correlated with confidence.

$$
R C=\frac{\left(V_{2} \rho_{2}-V_{1} \rho_{1}\right)}{\left(V_{2} \rho_{2}+V_{1} \rho_{1}\right)}=\frac{\left(A I_{2}-A I_{1}\right)}{\left(A I_{2}+A I_{1}\right)^{\prime}}
$$

where $\rho_{2}$ and $\rho_{1}$ represent densities of the first and second layers, respectively. $V_{2}$ and $V_{1}$ represent seismic velocities of the first and second layers, respectively.

In this study, seismic interpretation focuses on a particular area of interest within the two-way time (TWT) range of -1800 to $-2600 \mathrm{~ms}$ (Figure 5a). Depending on the seismic reflection discontinuities and terminations, the manual horizon picking followed by seeded horizons auto-tracking was adopted to interpret the target horizons on 2D cross-sectional (i.e., vertical) slices of a 3D seismic volume. In the middle part of the seismic cross-sections, the reflections are mostly moderately chaotic and strenuous to correlate due to the complexity of geology and faults resulting from tectonic compression (Figure 5b).

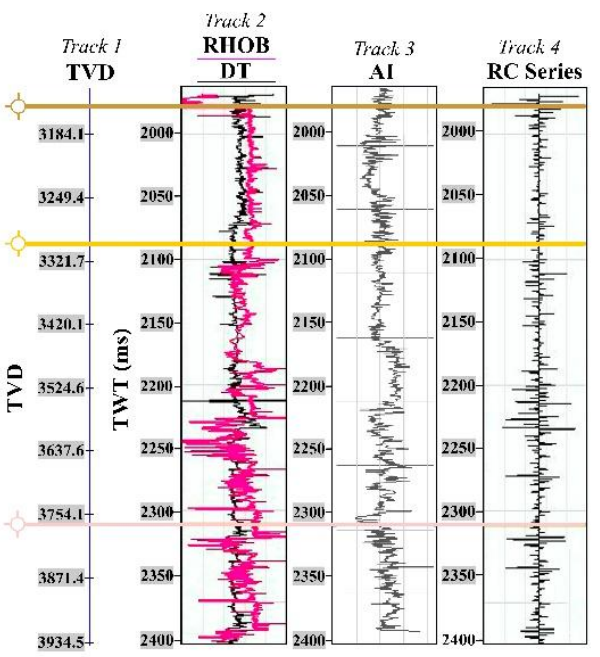

(a)

Figure 4. (a) Workflow of the synthetic seismogram generation; (b) RHOB and DT logs in Track 2 were combined to generate AI and RC series (Track 3 and 4, respectively). RC and Ricker wavelets were integrated to generate synthetic seismogram, which was then tied back to seismic data by adjusting a bulk shift.

The interpretation of subsurface geological structure and its lateral and horizontal extent depend on the TWT contours surfaces, which are identified and picked according to the seismic reflector (stratigraphic interface) in the two-way vertical time unit calibrated with the wireline logs [10]. Consequently, 3D TWT contour surfaces were constructed by marking the top of each stratigraphic interface on the extended 3D seismic volume. The smooth function was then applied to the generated surfaces at three iterations level to deliver geologically reasonable stratigraphic surfaces. These 3D TWT contour surfaces were conventionally used to interpret the prevailing structural trends in the study area. 

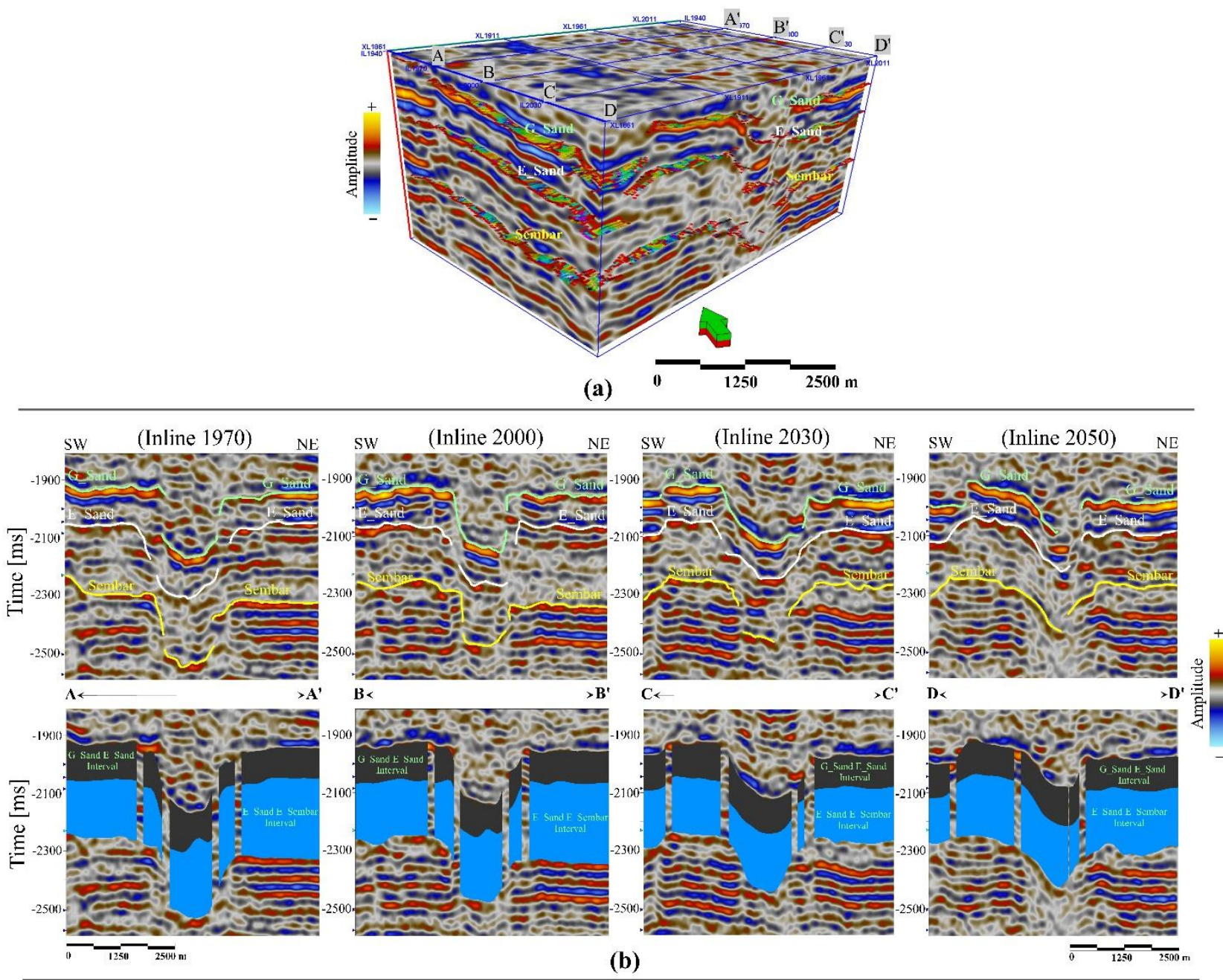

Figure 5. (a) 3D time seeded horizon auto-tracking; (b) Amplitude display of vertical time inline cross-sections (e.g., 1970, 2000, 2030, and 2050) in the SW to NE direction show horizons interpretation (above row) and corresponding horizons structural feature analysis (below row). Mint green, white, and yellow colors represent the lateral extent of $G$ sand interval, E sand interval, and the Sembar Formation, respectively. The interpreted stratigraphic interfaces constrained can be exported and processed to create 3D TWT contour surfaces.

\subsubsection{D Fault System Modeling (FSM)}

3D FSM in the seismic analysis is a crucial step to constrain the horizon interpretation [23,31,53]. The significant recent advance in FSM has been the routine availability of 3D seismic reflection surveys that provide detailed images of large volumes of rock and the often complex 3D fault networks [54]. Meanwhile, most seismic datasets have signal disturbance zones, particularly in highly faulted areas; discontinuities in seismic reflectors can be poorly resolved, resulting in an approximate location or misinterpretation of faults. However, seismic discontinuities could be more clearly defined if the detection is based on multiple attributes and suitable filters $[54,55]$. In this study, before proceeding to the 3D FSM, the precision of the geologic faults boundaries was reviewed first for accuracy using dip magnitude and seismic edge enhancement attributes (Figure 6). The dip magnitude is analogous to the strike and dip of sedimentary layers. It involves extracting the deviation of a seismic reflector from a horizontal plane (Figure 6a). However, the edge enhancement attribute reveals discontinuities related to stratigraphic terminations or structural lineaments, therefore valuable to identify faults (Figure 6b). Accordingly, the dominance of normal faults system was interpreted on dip magnitude and edge enhancement cross-sections by 


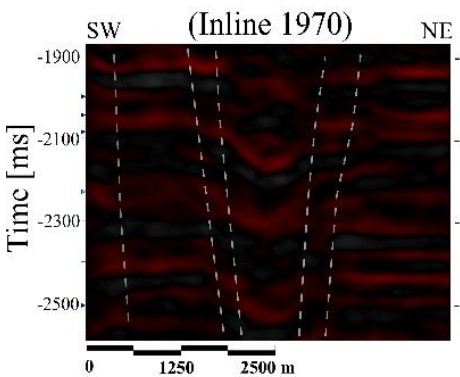

aligning reflector discontinuities and amount of displacement. The faults system interpreted on adjacent seismic lines that are judged to be from the same faults were assigned with the same label (points) (Figure 7a). The individual fault points were correlated to define the geometry of fault surfaces in 3D space (Figure $7 \mathrm{~b}$ ). The fault surfaces were constructed by employing the fault polygon in Petrel ${ }^{\mathrm{TM}}$ software for each type of fault with various geometrical structures, each congruous to its polygon. The primary faults surfaces were then defined by implementing fault polygons with varying stratification planes (Figure 7c). Finally, 3D FSMs and their attribute models (e.g., dip angle, fault rose diagram and histogram) were constructed to evaluate fault system geometric distribution and mechanics within the early Cretaceous stratigraphic sequence.
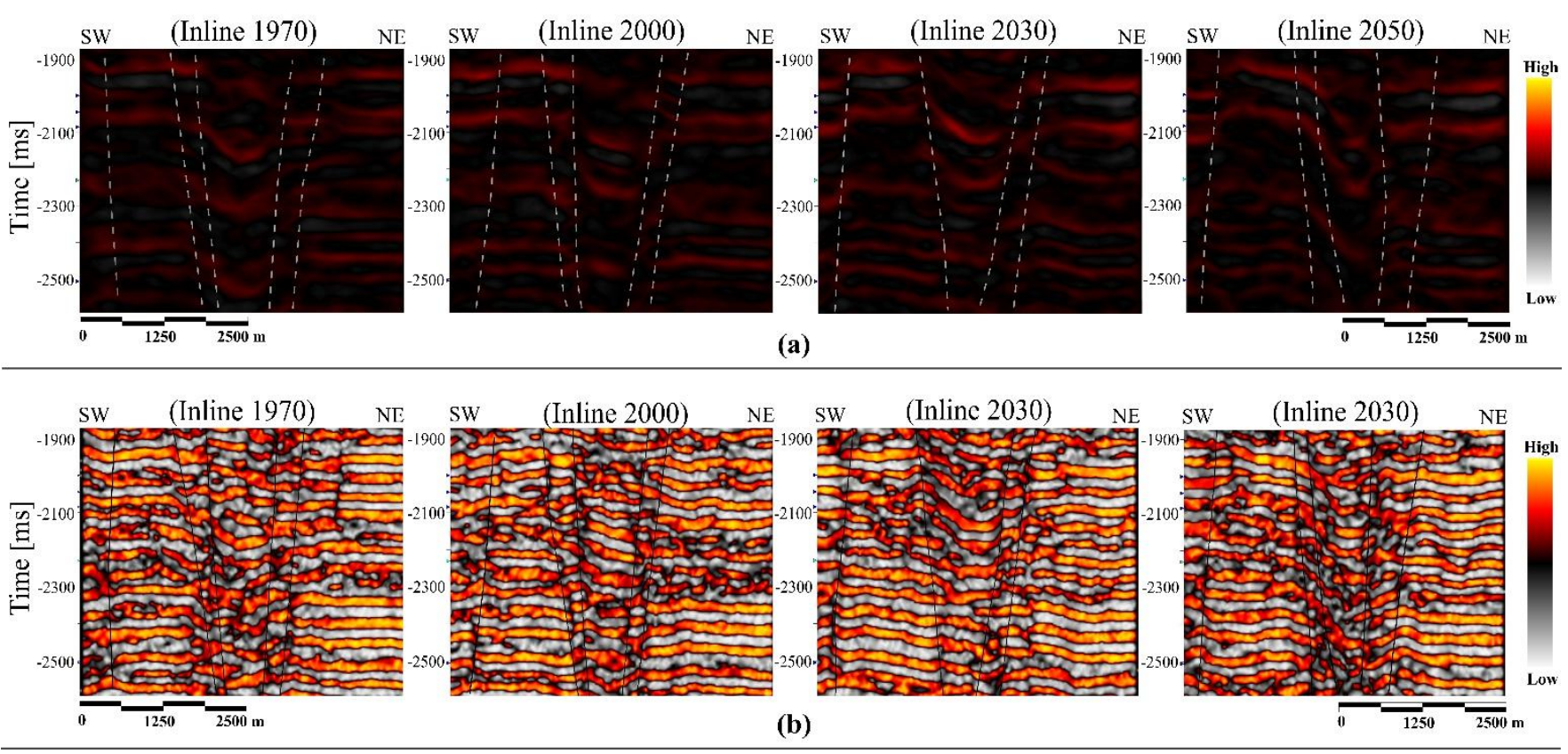

Figure 6. Faults system tracing and interpretation in the Kadanwari field using resemble brittle deformation features (seismic reflection discontinuities, terminations, and amount of displacement) on (a) dip magnitude and (b) seismic edge enhancement attributes cross-sections.

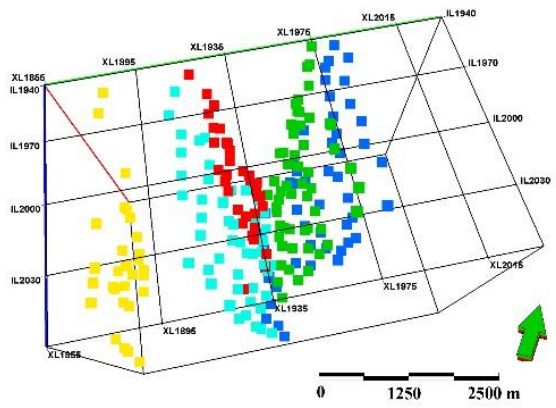

(a)

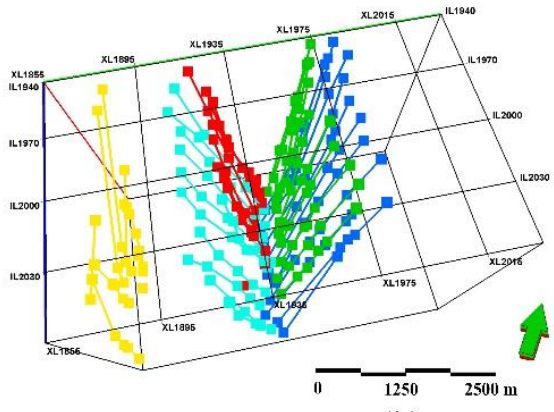

(b)

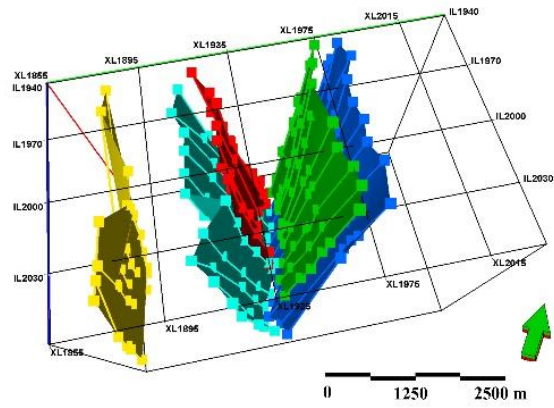

(c)

Figure 7. The employed primary steps to construct 3D FSMs: (a) assigning fault labels (points) on seismic sections; (b) assigning fault labels with corresponding lines; and (c) constructing fault polygons (surfaces) in 3D space.

\subsubsection{D structural modeling (3D SM)}

3D SM aims at better imaging and understanding the complex reservoir geological structures. The local tectonics of the Kadanwari field in MIB resulted in various structural deformations that led to many uncertainties in understanding the 3D reservoir 
structural framework [7]. The understanding of such deformations can be better comprehended by 3D SM using relevant algorithm models, e.g., volume-based modeling (VBM) in the Petrel ${ }^{\mathrm{TM}}$ modeling software, which is based on the interpreted seismic data integrated with borehole information [1,2,12,53,56,57]. Traditional modeling methods generally require oversimplification of geological settings; however, grid-generated VBM captures realistic reservoir architecture [2]. These can be easily transferred into the dynamic realm providing a better understanding of the reservoir for future field management and development [53]. In this study, 3D SM based on the VBM approach was performed primarily in three main steps (e.g., faults modeling, pillar gridding, and horizon creation). The faults modeling process involves inserting the interpreted faults system into the structural model to form a framework for creating the 3D structural grid. The second step is pillar gridding, which includes constructing the structural grid from the fault models by creating key pillars representing a line with top, middle, and bottom points $[53,56]$. The third step includes making horizons by constructing the vertically stacked layers by placing the interpreted seismic horizons into the gridded model.

\subsubsection{D Seismic Attribute Analysis}

Seismic attributes were computed by mathematical manipulation of the original seismic data to highlight specific geological, physical, or reservoir properties, which are unrecognizable via the original seismic amplitude data [58,59]. Variations in the amplitude, phase, frequency, and bandwidth of the seismic waves were subsequently used to validate the spatial forecasts of the geological structure and to evaluate the spatial distribution of the facies and potential hydrocarbon zones at the $\mathrm{G}$ sand interval, E sand interval, and the Sember Formation time windows. The applied seismic attributes include variance edge, sweetness, and root mean square (RMS) amplitude.

(1) The variance edge attribute was used to delineate prominent faults and seismic amplitude discontinuity in both horizon slices and vertical seismic profiles, thus validating the manual interpretation of faults. The variance edge attribute measures the similarity of seismic waveforms or adjacent traces in given lateral and vertical windows. Therefore, it can visualize the seismic amplitude discontinuity related to faulting or stratigraphy [60];

(2) The sweetness attribute was applied to both horizon slices and vertical seismic profiles to identify sweet spots zones that are hydrocarbon prone. It can be defined as the reflection strength (instantaneous amplitude) divided by the square root of instantaneous frequency. The high sweetness anomalies highlight high amplitudes and low frequency content of a seismic signal and vice versa. Therefore, combining these two physical quantities helps distinguish sand bodies from the shale and predicted gas prone zones [61];

(3) The RMS amplitude attribute was applied to both horizon slices and vertical seismic profiles to measure amplitude anomalies, to identify the spatial distribution of facies, and to model hydrocarbon zone at $G$ and $E$ sand reservoir intervals. The RMS amplitude computes the square root of the sum of squared amplitudes divided by the number of samples within the specified window used [20].

\subsubsection{Petrophysical modeling}

Petrophysical modeling is critical in a reservoir study because it provides a primary input data source for integrated reservoir characterization and resource evaluation $[2,17,19,57]$. In this study, petrophysical modeling was performed based on wireline logs data and internal geological reports to evaluate $G$ and $E$ sand reservoir intervals properties, e.g., lithology, $V_{\text {shale, }} \emptyset_{\text {avg, }} \emptyset_{\text {eff, }} S_{\mathrm{W}}$, and $S_{\text {hc }}$ (Table 4). The successful evaluations of these properties are necessary for determining the hydrocarbon potential of a reservoir system's performance. The wireline logs data for the studied reservoir intervals comprise conventional logs (e.g., GR, SP, LLD, LLS, MSFL, RHOB, NPHI, and DT) of the Kadanwari-10 and Kadanwari-11 wells. The concise, detailed plot of wireline logs curves and their depth ranges within $G$ and E sand reservoir intervals are shown in Figure 8,9, 
respectively. These log curves express the physical motifs of the stacked geological strata as a function of depth, which can identify lithologies, porosities, and differentiate between porous and non-porous rocks and pay zones. The following five key steps were followed in order to evaluate fundamental reservoir properties.

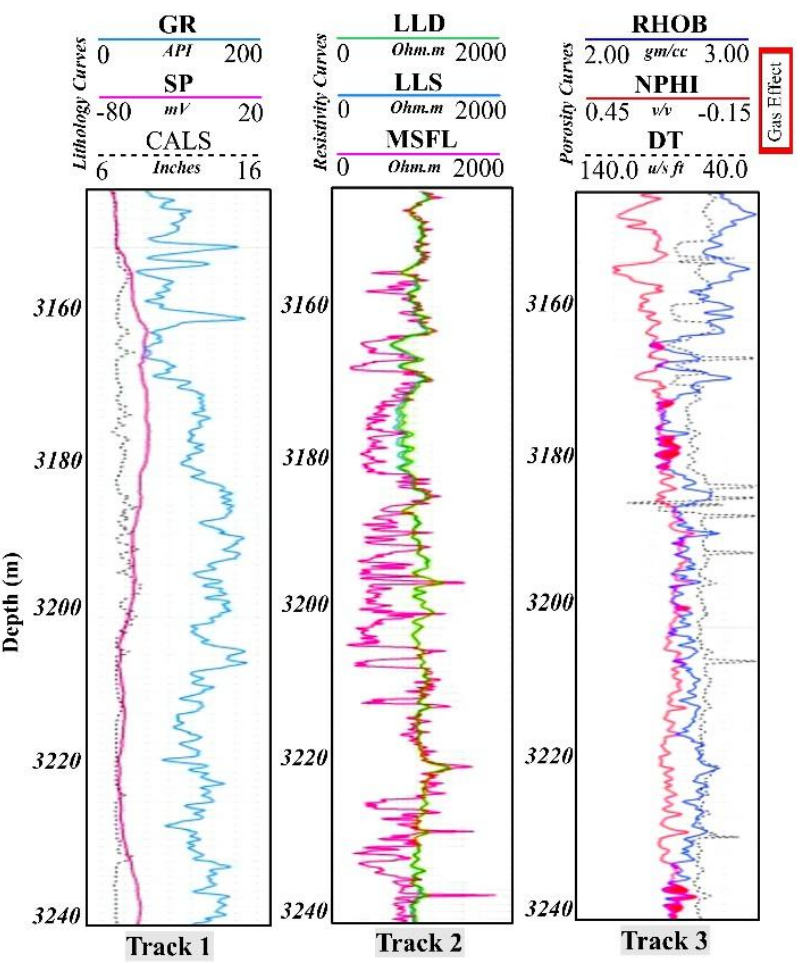

(a)

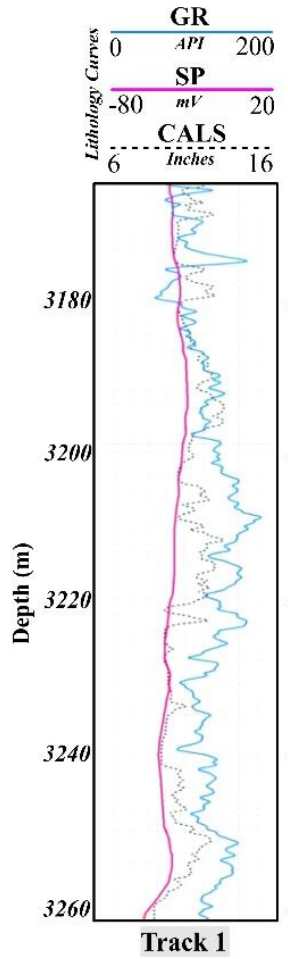

Track 1

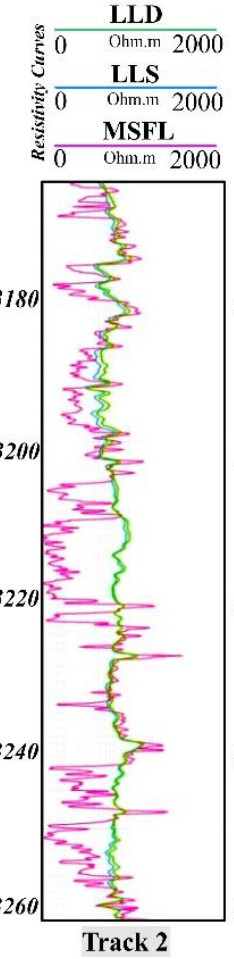

(b)

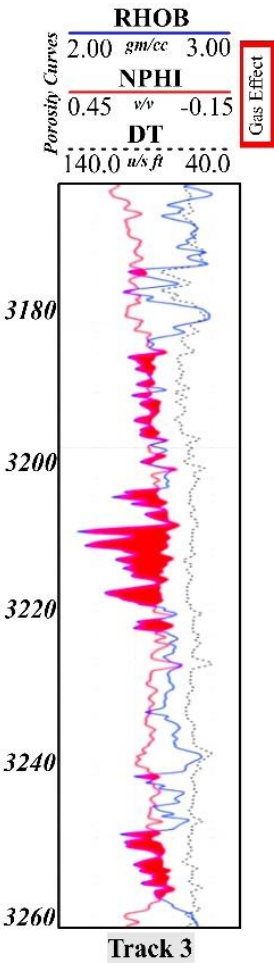

Track 3

Figure 8. Input conventional logs curves (e.g., CALI, GR, and SP in track 1, LLD, LLS, and MSFL in track 2, RHOB, NPHI, and DT in track 3) for petrophysical modeling of G sand interval in (a) Kadanwari-10; (b) and Kadanwari-11 wells.
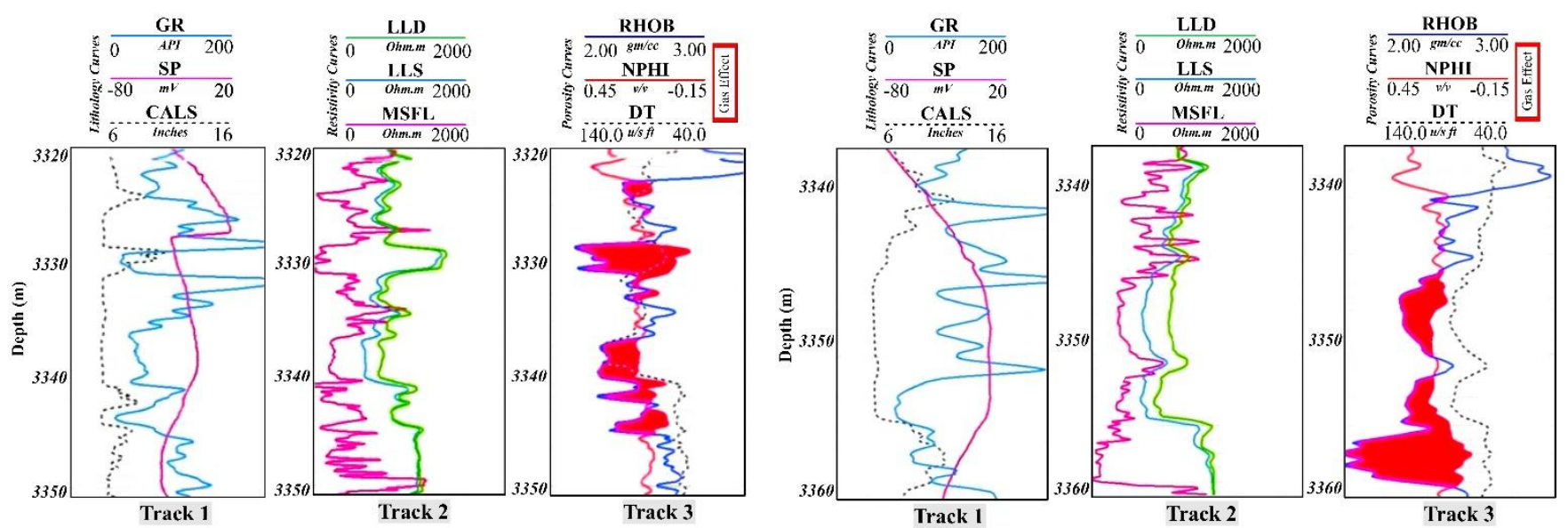

Figure 9. Input conventional logs curves (e.g., CALI, GR, and SP in track 1, LLD, LLS, and MSFL in track 2, RHOB, NPHI, and DT in track 3) for petrophysical modeling of E sand interval in (a) Kadanwari-10; (b) and Kadanwari-11 wells.

(1) Volume of Shale $\left(\mathrm{V}_{\text {shale }}\right)$ : The presence of shale in the productive zone severely impacts the petrophysical properties and can cause a reduction in the $\emptyset_{\text {eff, }} \emptyset_{\text {avg, }}$ and permeability. Moreover, it also poses problems in the interpretation of wireline well logs and can affect proper and effective estimation of $S_{\mathrm{hc}}$ [62]. Several methods are usually used for $\mathrm{V}_{\text {shale }}$ estimation, such as GR $\log$, SP $\log$, or porosity-neutron log 
$[17,24]$. We used the GR log technique for the $\mathrm{V}_{\text {shale }}$ estimation by first estimating the gamma-ray index $\left(\mathrm{I}_{\mathrm{GR}}\right)$. The $\mathrm{I}_{\mathrm{GR}}$ was initially adopted using Equation 2 to estimate $\mathrm{V}_{\text {shale }}$ by utilizing the $\mathrm{GR}_{\log }$ in track 1 in Figure 7,8, respectively. Secondly, to obtain the realistic $V_{\text {shale }}$ estimation without overestimating the content of shale (first-order approximation: $\mathrm{V}_{\text {shale }}=\mathrm{I}_{\mathrm{GR}}$ ), a non-linear relationship (Equation 3) proposed by Dolan was employed [63].

$$
\begin{gathered}
I_{G R}=\frac{G R_{\log }-G R_{\min }}{G R_{\max }-G R_{\min }}, \\
V_{\text {shale }}=1.7-\left[\left(3.38-\left(I_{G R}+0.7\right)^{2}\right)\right]^{\frac{1}{2}},
\end{gathered}
$$

where, $I_{G R}$ stands for the gamma-ray index, $G R_{\log }$ shows the reading of the gamma-ray $\log , G R_{\min }$ and $G R_{\max }$ are the lower and upper limits of $G R_{\log }$ reading in shale, respectively.

(2) Average Porosity $\left(\emptyset_{\text {Avg }}\right)$ : Total porosity or $\emptyset_{\text {Avg }}$ represents all the voids or pore spaces of the rock, including interconnected and isolated pores and pore space occupied by clay-bound water [2]. In this study, DT, RHOB, and NPHI logs that are sensitive to sedimentary micro-facies were selected to calculate $\emptyset_{\text {Avg, }}$ by which the conventional logging responses of $\mathrm{G}$ and $\mathrm{E}$ sand reservoir intervals are summarized (Figure 8,9).

The DT log measures the sound waves' traveling times in the rock unit. The sound waves in the rock unit depend on the shape, matrix material, and cementation (Equation 4). Accordingly, the Sonic-Raymer (SR) porosity model was used to evaluate sonic porosity $\left(\emptyset_{S}\right)$ (Equation 5) [42].

$$
\begin{gathered}
t_{l o g}=t_{m}-\left[\left(1-\emptyset_{S}\right)+t_{f} \emptyset_{S}\right], \\
\emptyset_{S}=\frac{\Delta t_{\text {log }}-\Delta t_{m}}{\Delta t_{m}-\Delta t_{m}},
\end{gathered}
$$

where, $\emptyset_{S}$ represents sonic porosity, $\mathrm{t}_{\log }$ represents the log reading in $\mu \mathrm{sec} / \mathrm{m}, t_{m}$ represents matrix interval transient time, $\Delta t_{\log }$ represents formation interval transient time in $\mu \mathrm{sec} / \mathrm{m}$, and $\Delta t_{m}$ represents formation fluids interval transient time in $\mu \mathrm{sec} / \mathrm{m}$.

The density porosity $\left(\emptyset_{\mathrm{D}}\right)$ was calculated using RHOB $\log$ as Equation $6[2,64]$.

$$
\phi_{D}=\left[\left(\rho_{m a t}-\rho_{b}\right) /\left(\rho_{m}-\rho_{f}\right)\right],
$$

where, $\rho_{\text {mat }}$ represents the density of the matrix, $\rho_{f}$ represents the fluid density, and $\rho_{b}$ is the bulk density.

The NPHI log measures the neutron porosity $\left(\emptyset_{\mathrm{N}}\right)$ by considering that the pores are filled with fluids. Therefore, it measures the hydrogen concentration and energy loss. The $\emptyset_{\mathrm{N}}$ can be expressed as Equation 7.

$$
\phi_{N}=[\mathrm{a} N+\mathrm{b}],
$$

where $\phi_{N}$ is the neutron-derived porosity, a and b are constants, and $N$ is the neutron count in the formation intervals. In addition, the density-neutron cross-plot in track 4 in Figure 8 and 9 determine cross-over gas effects.

After identifying porosities (e.g., $\emptyset_{\mathrm{S}}, \emptyset_{\mathrm{D}}$, and $\emptyset_{\mathrm{N}}$ ) from DT, RHOB, and NPHI logs, Equation 8 was used to calculate $\emptyset_{\mathrm{Av}} \mathrm{g}$ [64].

$$
\emptyset_{\text {Avg }}=\frac{\emptyset_{S}+\emptyset_{D}+\emptyset_{N}}{3},
$$

(3) Effective Porosity $\left(\emptyset_{\text {eff }}\right)$ : The $\emptyset_{\text {eff }}$ was calculated using the following Equation 9 $[42,50]$. 


$$
\phi_{\text {eff }}=\left[\left(\phi_{\text {Avg }}\right) \times\left(1-V_{\text {shale }}\right)\right],
$$

where, $\emptyset_{\mathrm{Avg}}$ represents the average porosity, and $\mathrm{V}_{\text {shale }}$ is the shale content in volume units.

(4) Water Saturation $\left(S_{W}\right)$ : Identifying $V_{\text {shale }}$ in the reservoir is crucial for selecting the appropriate model for calculating the $S_{w}$ in shaly sand reservoirs. The Poupon-Leveaux Indonesian (PLI) model is one of the best models to estimate $S_{W}$ in the shaly sand reservoir [65]. In this study, the constraints of $V_{\text {shale }}$ (Equation 3), $\emptyset_{\text {eff }}$ (Equation 9), and resistivity variation in $\mathrm{V}_{\text {shale }}$ and water formation were subsequently integrated using the PLI model as Equation 10 to determine $S_{W}$ [65].

$$
S_{w}=\left\{\left[\left(\frac{V_{\text {shale }}{ }^{2-V_{\text {shale }}}}{R_{\text {shale }}}\right)^{2}+\left(\frac{\emptyset_{\text {eff }}{ }^{2}}{R_{w}}\right)^{\frac{1}{2}}\right]^{2} R_{t}\right\}^{2}
$$

where $R_{t}$ is the true resistivity of the formation obtained from the LLD log response, $R_{\text {shale }}$ is the resistivity variation in the $V_{\text {shale }}$, and $R_{w}$ is the resistivity of water formation.

(5) Hydrocarbon Saturation $\left(S_{h c}\right)$ : The calculation of $S_{h c}$ is essential because it decides whether the company proceeds to further exploration and production activities in the field [22]. The $S_{\mathrm{hc}}$ was calculated by subtracting the percentage of pore volume occupied by $S_{\mathrm{w}}$ from 1 , and the remained percentage pore volume represents the $S_{\mathrm{hc}}$ (Equation 11).

$$
S_{h c}=1-S_{w}
$$

\section{Results}

\subsection{Stratigraphic Interfaces Interpretation}

The interpretation of the stratigraphic interfaces of the Early Cretaceous sequence is integrated into an internally consistent 3D workflow, which is easy to incorporate and conclude beyond known points to constrain 3D structural models. The interpreted cross-sectional (i.e., vertical) slices of a 3D seismic volume show the displacement and deformation of the stratigraphic interface (Figure $5 b$ ). The structural variations of the stratigraphic interfaces are primarily predicated based on the TWT contour surfaces because contour lines depict lines connecting the same elevation, that is why they are essential tools for analyzing and interpreting seismic data. The time surfaces plot the TWT of seismic signals from the surface to the horizon and reflect the interpreted stratigraphic interface distribution. In Figure 10, the TWT surfaces explicate the extension and propagation of the regional stratigraphic structure in the subsurface. The TWT values of the interpreted stratigraphic interfaces decrease towards the central part of the field, which gives rise to structural highs at its southwestern and southeastern portions. The southwestern and southeastern portions of the interpreted stratigraphic interfaces are structurally high; hence it is a region of interest for hydrocarbon exploration. The minimum, mean and maximum TWT variation of $\mathrm{G}$ sand interval, $\mathrm{E}$ sand interval, and the Sembar Formation in the southwestern and southeastern transect are presented in Table 5.

Table 5. Minimum, mean, and maximum TWT variations of stratigraphic interfaces in the study area.

\begin{tabular}{cccccc}
\hline Stratigraphic Interfaces & $\begin{array}{c}\text { TWT } \\
\text { Minimum }\end{array}$ & $\begin{array}{c}\text { TWT } \\
\text { Mean }\end{array}$ & $\begin{array}{c}\text { TWT } \\
\text { Maximum }\end{array}$ & $\begin{array}{c}\text { Shallow Structure } \\
\text { (TWT) }\end{array}$ & $\begin{array}{c}\text { Deep Structure } \\
\text { (TWT) }\end{array}$ \\
\hline G sand interval & $-1900(\mathrm{~ms})$ & $-2037.5(\mathrm{~ms})$ & $-2175(\mathrm{~ms})$ & -1900 to $-2025(\mathrm{~ms})$ & -2026 to $-2175(\mathrm{~ms})$ \\
\hline
\end{tabular}




\begin{tabular}{cccccc}
\hline E sand interval & $-2025(\mathrm{~ms})$ & $-2187.5(\mathrm{~ms})$ & $-2350(\mathrm{~ms})$ & -2025 to $-2100(\mathrm{~ms})$ & -2101 to $-2350(\mathrm{~ms})$ \\
Sembar Formation & $-2250(\mathrm{~ms})$ & $-2400(\mathrm{~ms})$ & $-2550(\mathrm{~ms})$ & -2250 to $-2375(\mathrm{~ms})$ & -2376 to $-2550(\mathrm{~ms})$ \\
\hline
\end{tabular}
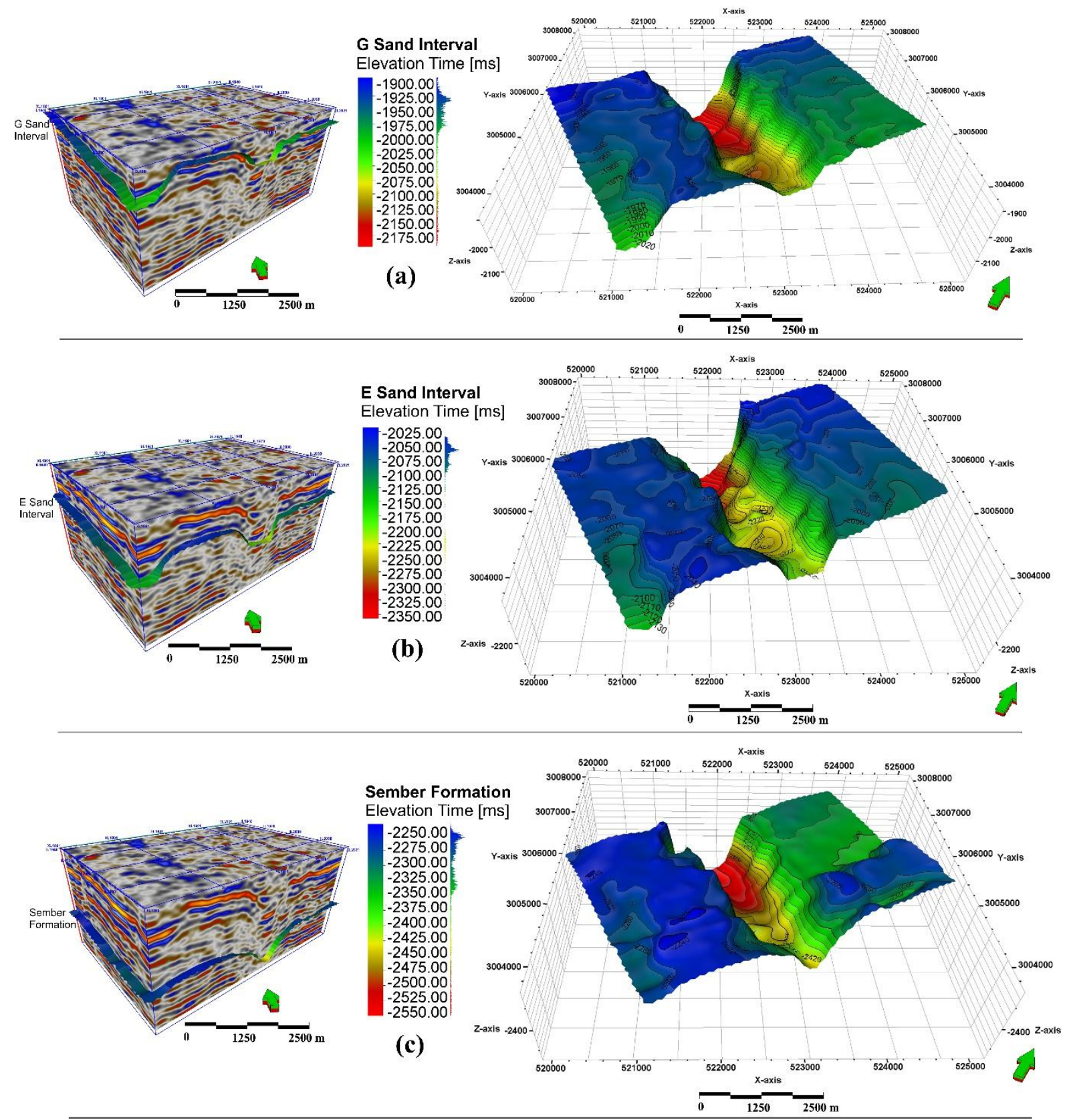

Figure 10. 3D TWT contour surfaces of the stratigraphic interfaces show different structural distribution: (a) TWT top surface of G sand interval; (b) TWT top surface of E sand interval; (c) TWT top surface of the Sembar formation in 3D space. The geometry of these surfaces can be used to construct the 3D SMs.

\subsection{D Fault System Models (FSMs)}

\subsubsection{Seismic Data Analysis}

Fault mechanisms play a vital role since they controlled the evolution of basins or formations and involved crucial processes such as hydrocarbon entrapment, seals, and the development of hydrocarbon migration pathways [2]. The study area's complex and composite subsurface morphology resulted from multiple tectonic activity episodes. Multi-stage tectonic movements contribute to the intersection of the faults formed 
simultaneously or faults formed at different stages of tectonic movements (Figure 11). The Indus Basin Pakistan is related to the fact that many hydrocarbon fields have been discovered on the closure of normal faults characterized by extensional tectonic settings $[48,52]$. According to regional studies of the tectonic setting of the study area, the initiation of rifting of the Indian Plate 130 Ma had led to the development of an extensional faults system [7]. These faults occurred during various phases of adjustment and deformation, along with the structure inversion and loss of reservoir quality in the Kadanwari field, MIB. The late Paleocene wrenching is the most structural event affecting the subsurface geological structure of the study area. However, the final tectonic event that significantly influenced the Kadanwari field is a late Tertiary to Quaternary inversion of the Jacobabad-Khairpur High.
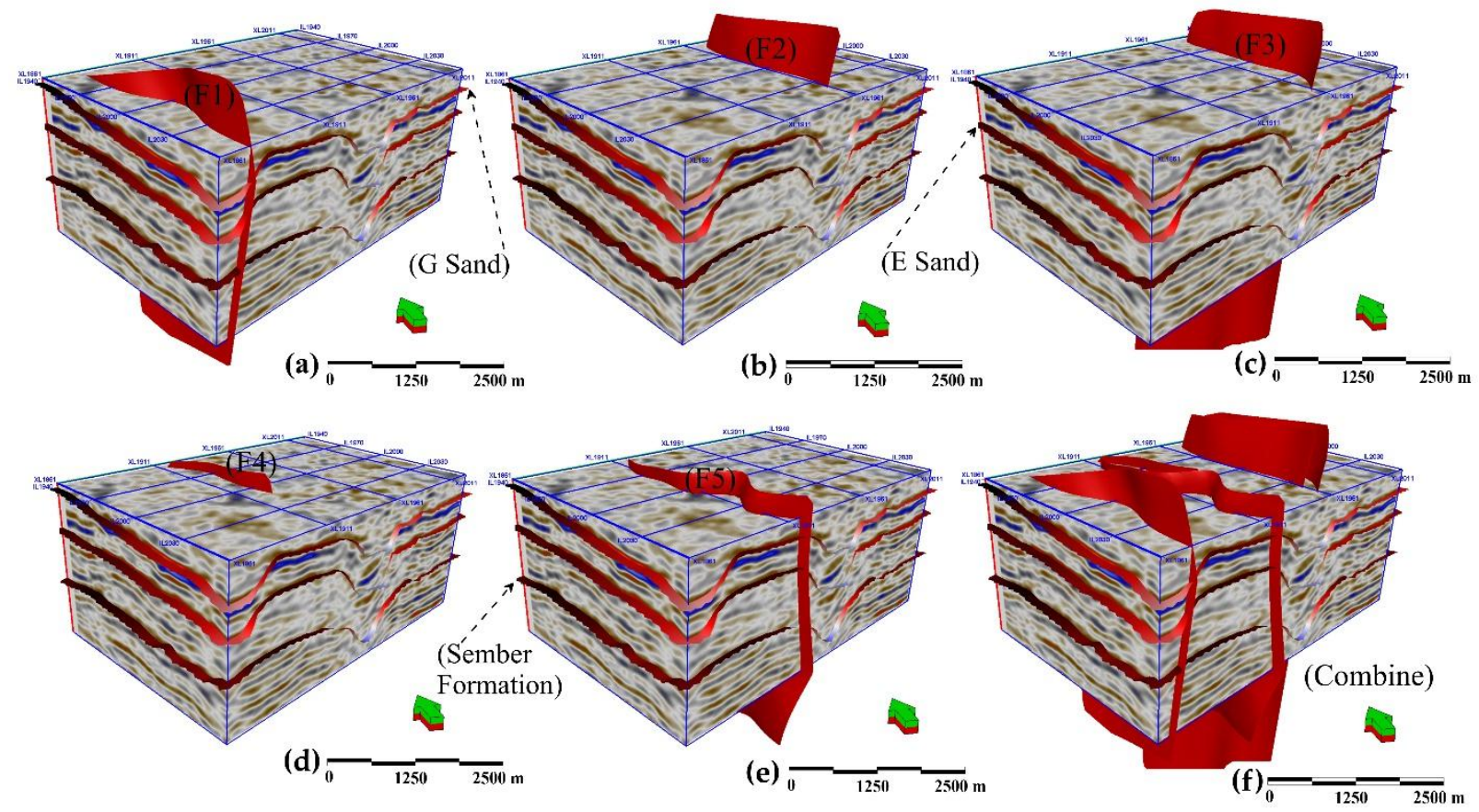

Figure 11. The individual faults surfaces: e.g., (a) F1; (b) F2; (c) F3; (d) F4; (e) F5; (f) and its combined distribution in the 3D seismic volume (SW-SE view) showing the distribution of the tectonic extensional faults cutting the early Cretaceous stratigraphic sequence.

\subsubsection{Spatial Distribution of the Fault System}

In order to reasonably represent the spatial distribution of the fault system and its influence on the fragmentation of the stratigraphic interfaces, the individual 3D fault surfaces were drawn along with the 3D seismic volume (Figure 11). The orientation and distribution of fault surfaces revealed that the intact depositional environment of the Kadanwari field was influenced by the tectonic regime of the surrounding plate boundary, which continuously influenced the stratigraphic structure. The interpretation of the field scale shows that the middle part of the 3D seismic volume has undergone more deformation than both sides of the seismic volume, that is why the number of faults and their complexity decrease from the center to both sides of the field. These faults were interpreted as normal faults, trending NW to SE directions that controlled the distribution of depositional facies, reservoir compartmentalization, and hydrocarbon up-dip migration in the study area. These NW-SE normal faults governed the complex structural configuration of stratigraphic sequence (e.g., G sand interval, E sand interval, and Sembar Formation). The overall pattern of these faults can be regarded as a negative flower structure, which significantly increases the likelihood of the successful positioning of hydrocarbon traps. The degree of completion of these negative flower structures is positively correlated with improving hydrocarbon migration and 
abundance in the reservoir window (e.g., G sand and E sand intervals). In addition, the presence of negative flower structure indicates the combined effects of extensional and strike-slip motion.

The fault orientation results derived from the 3D dip angle models, steroenet, rose diagram, and histogram are shown in Figures 12 and 13, respectively. The faults trends in the 3D dip angle models, steroenet and rose diagram show that most of the faults are oriented in $\mathrm{S} 30^{\circ}-45^{\circ} \mathrm{E}$ and $\mathrm{N} 25^{\circ}-35^{\circ} \mathrm{W}$ with azimuth as $148^{\circ}-170^{\circ}$, and $318^{\circ}-345^{\circ}$, and exhibiting minimum, mean and maximum dip angles $28^{\circ}, 62^{\circ}$, and $90^{\circ}$ respectively. The histogram in Figure 13b displays the relationship between fault frequency in percentage and dip angle in degrees, which specifies that most of the faults have dips ranging between $35^{\circ}$ and $75^{\circ}$, while $20 \%$ of the total fault planes have dips in the range $80^{\circ}-90^{\circ}$, and the lowest fault dip observed is approximately $28^{\circ}$ (Figure 12,13a). The fault orientation and spatial distribution results derived from dip angle models, rose diagram, and histogram are in good agreement with the regional studies conducted by other scientists $[7,45,48]$.

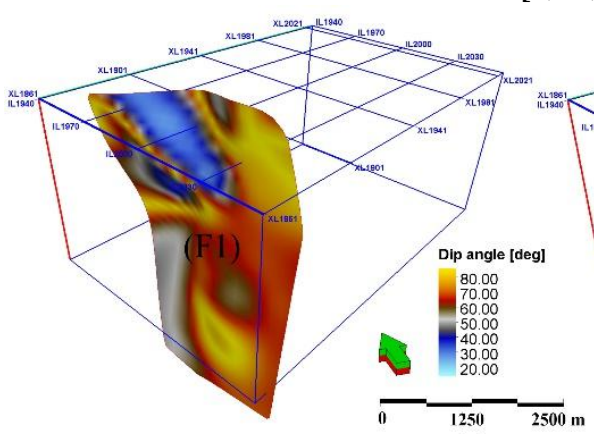

(a)

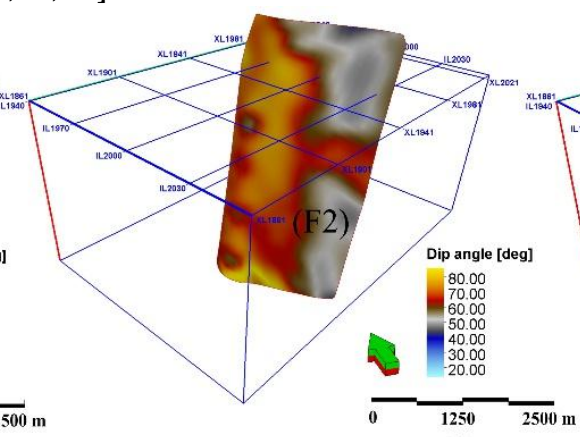

(b)

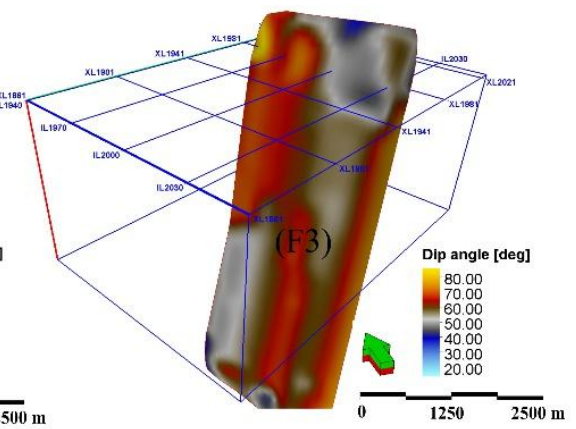

(c)

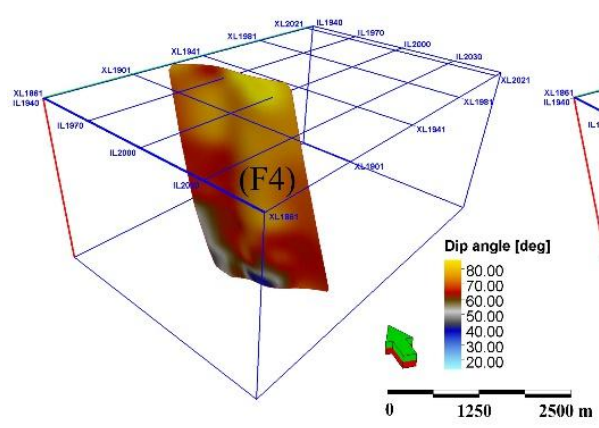

(d)

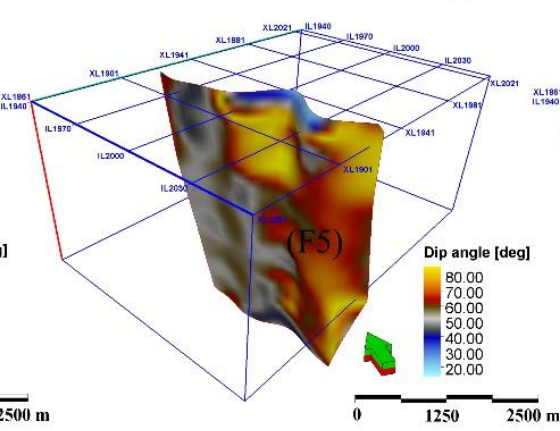

(e)

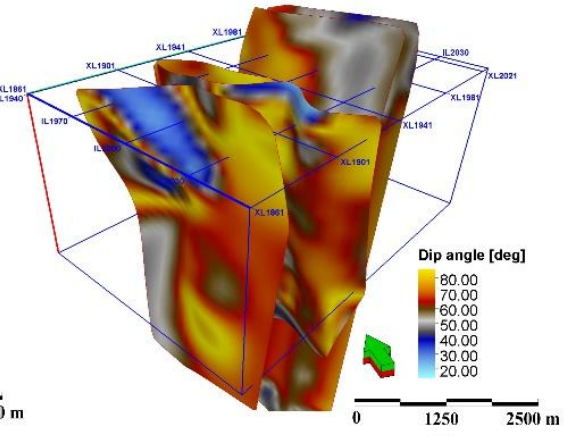

(f)

Figure 12. 3D dip angle models (SW-SE view) of the individual faults surfaces: (a) F1; (b) F2; (c) F3; (d) F4; (e) F5; and (f) the combined dip angle distribution in the study area.

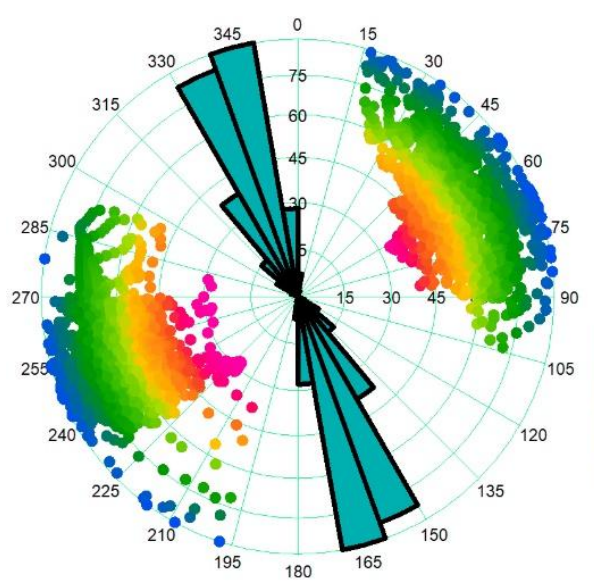

(a)

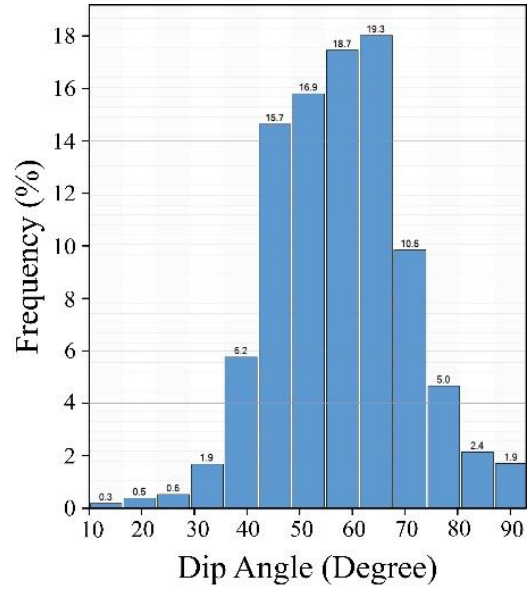

(b)

Dip Angle (Degree)
Dip angle [deg]

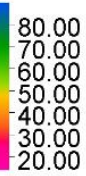

20.00 
Figure 13. (a) The steroenet with the distribution of regionally interpreted fault's dip and orientations identified along with the entire seismic survey in the Kadanwari field, MIB, Pakistan; (b) and a histogram showing the dip angles of the interpreted faults with their frequency.

\subsection{D Structural Models (3D SMs)}

We have assessed and visualized the 3D structural distribution of the early Cretaceous stratigraphic sequences, mainly showing faulting, the lateral and horizontal extent of the stratigraphic interfaces, and sequence compartmentalization. Moreover, several 2D time-domain structural cross-sections have been drawn from the 3D structural modeling output to delineate the detailed structural setting of the studied formations in the study area. Figure 14a displays the southwestern and southeastern transect of the 3D TWT model, while Figure 14b represents the 2D TWT cross-sections derived from the 3D TWT model result. Figure 15a displays the southwestern and southeastern transect of the 3D structural geological model derived from VBM, while Figure $15 \mathrm{~b}$ shows northeastern and northwestern parts views in 3D space. Moreover, the fault system is introduced into the 2D cross-sections during model computation to constrain the horizons at each fault offset (Figure 15c).

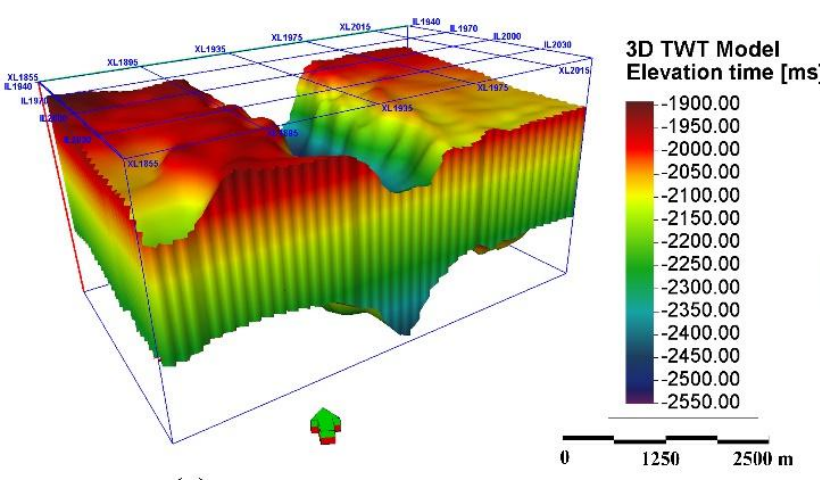

(a)

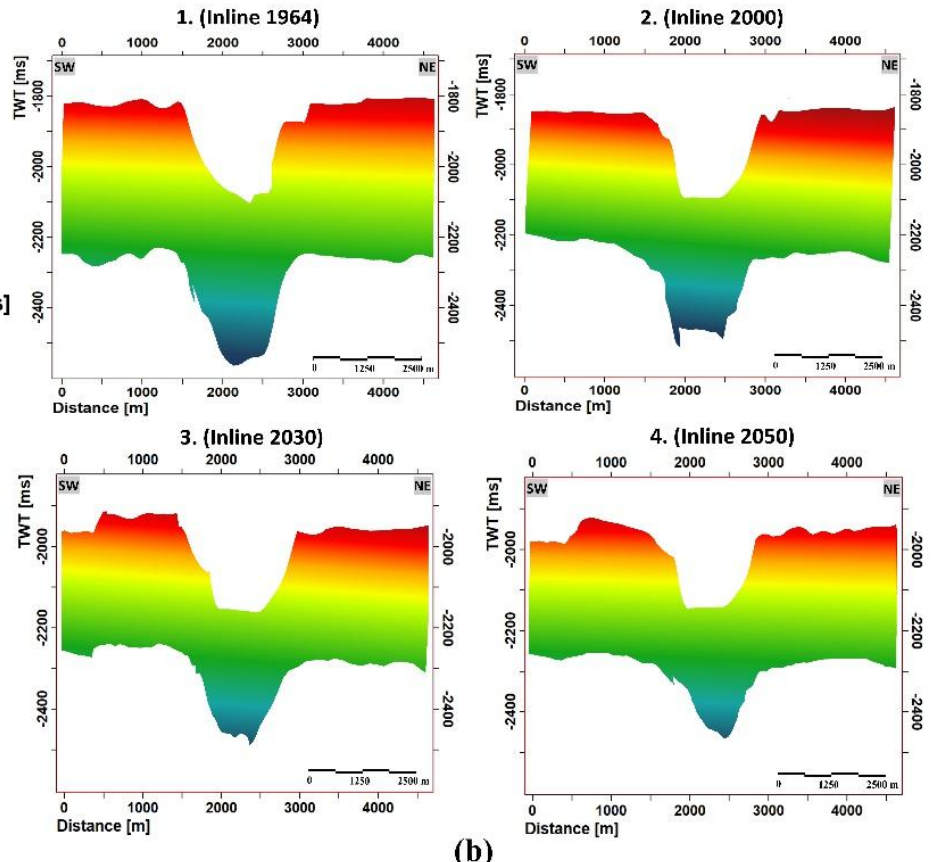

(b)

Figure 14. TWT domain structural model of the Early Cretaceous stratigraphic sequence (e.g., G sand interval, E sand interval, and the Sembar Formation): (a) SW-SE view; (b) Extracted inline 2D TWT cross-sections.

The detailed structural analysis reveals that the geological structural complexity is a consequence of different tectonic phases of deformation (e.g., extensional and strike-slip deformation from the early Cretaceous to Quaternary). The complex structural mechanics comprising both extensional and strike-slip movement have been observed in the 3D structural models. These complex structural mechanics were controlled by NW-SE dipping normal fault system. The explained normal fault patterns (e.g., negative flower structure) had resembled brittle deformation features where the interpreted sequences were displaced relative to each other (amount of displacement) (Figure 15c). It employed a significant control on structural domains consisting mainly, half-graben, horst, half-graben, graben, half-graben, and horst from SW to NE. It is observed that the thickness of the sequence increases towards the NE. At the top E sand interval to top Sembar Formation, the thickness decreases at the center portion. The spatial distribution 
and compositions of the fault system within the early Cretaceous sequences allow the hydrocarbon migration direction to be determined. The geometrical trend of these fault systems creates an essential pathway for hydrocarbon migration in the vertical direction. This up-dip migration of the hydrocarbons from the Sembar formation towards the $G$ and $\mathrm{E}$ sand intervals resulted in hydrocarbon accumulation, which are validated through seismic attributes analysis and petrophysical modeling.
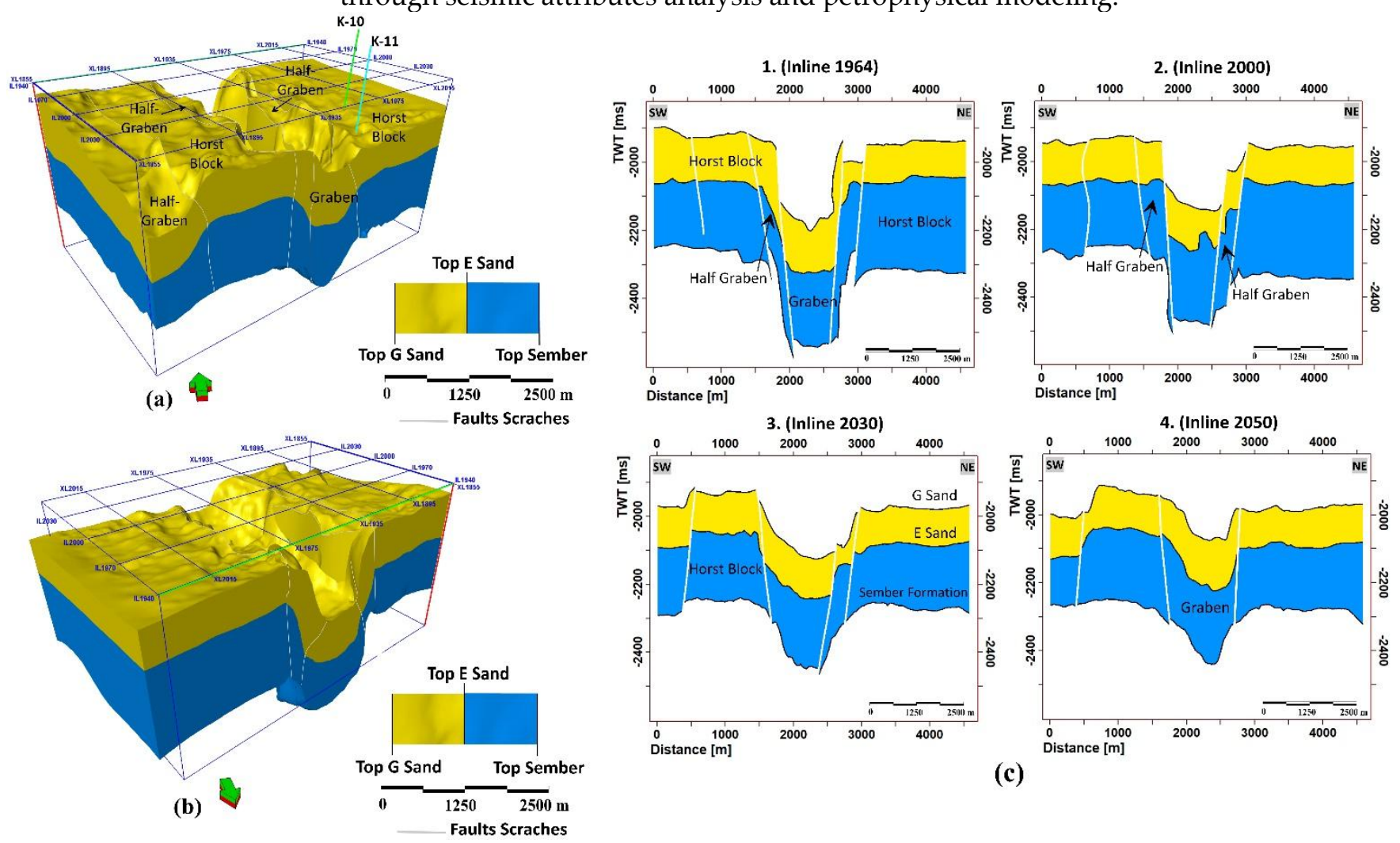

(c)

Figure 15. Final result of the 3D SMs: (a) SW-SE view; (b) NE-NW view; (c) and SW-NE oriented $2 \mathrm{D}$ cross-sections drawn from the 3D SMs results.

\subsection{Seismic Attributes Interpretation}

\subsubsection{Variance Edge Attribute}

The variance edge attribute signifies discontinuities related to faulting or stratigraphy in vertical seismic cross-sections and is proved to help image significant fault zones and fractures. Figure 16 shows the result of the variance edge attribute calculated from the 3D seismic volume, appropriate cross-sections (e.g., A-A', B-B', C-C', $\mathrm{D}-\mathrm{D}^{\prime}, \mathrm{E}-\mathrm{E}^{\prime}$, and $\mathrm{F}-\mathrm{F}^{\prime}$ ), and horizons slices. The horizons slices include $\mathrm{G}$ sand interval, $\mathrm{E}$ sand interval, and the Sembar Formation. The variance edge attribute values in the $2 \mathrm{D}$ variance cross-sections and horizons slices range from 0.0 to 1.0. A variance value equal to 1 indicates discontinuity, while continuous seismic events are explained with a value of 0 variances. The darkest regions (e.g., values range from 0.8 to 1 ) that make up vertical strips can be interpreted as faults or fractures. These faults and fractures create an essential pathway for hydrocarbon migration in the vertical direction. In addition, several bright spots indicate that the sediment has a higher reflectivity than the surrounding environment. These bright spots (red areas) represent high reflectivity sediments that might be potential hydrocarbon traps in the study area (Figure 16c). 


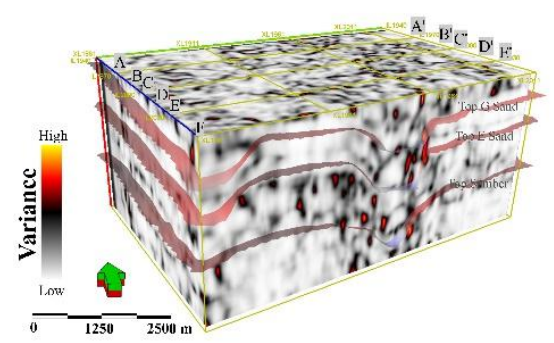

(a)
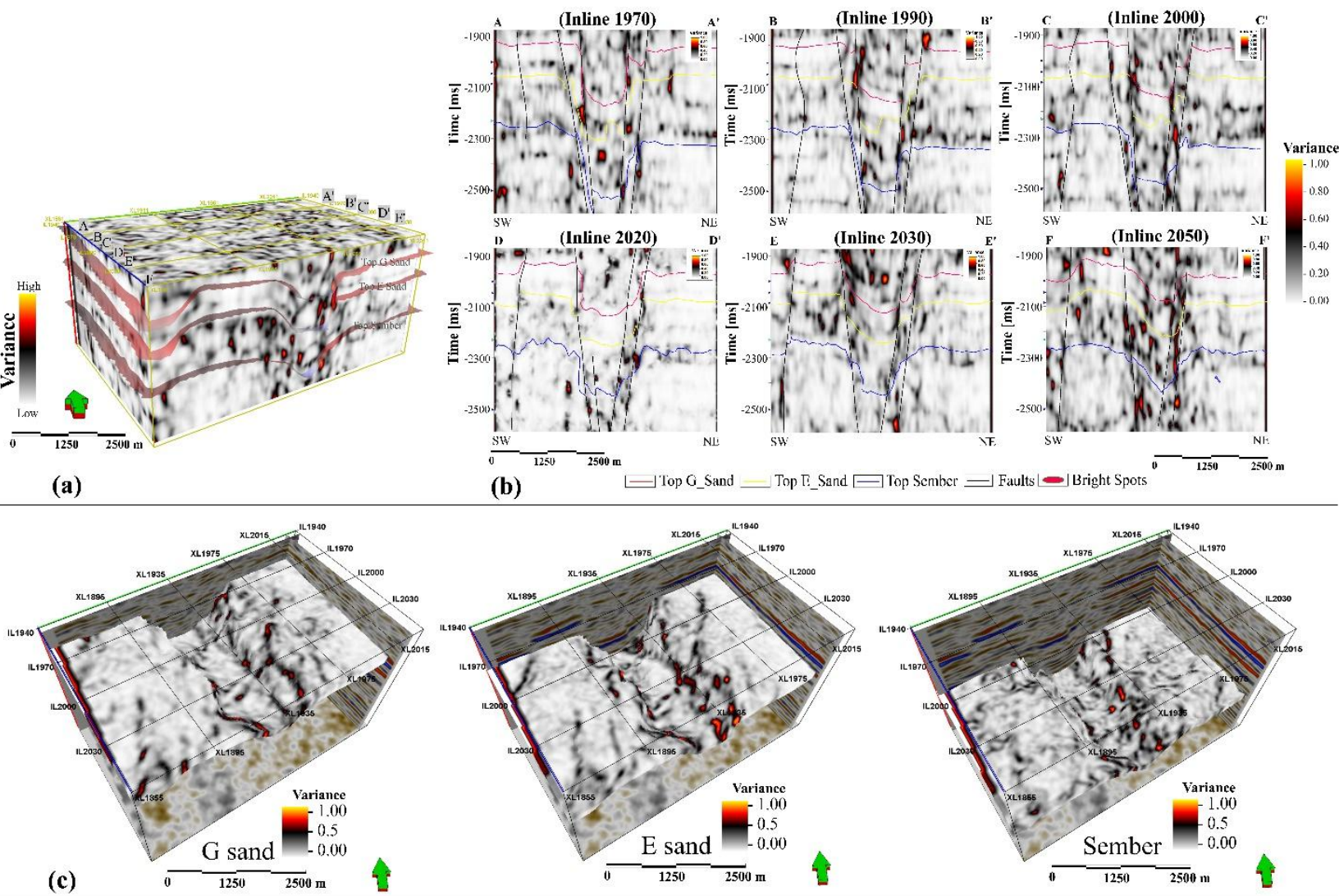

(b)
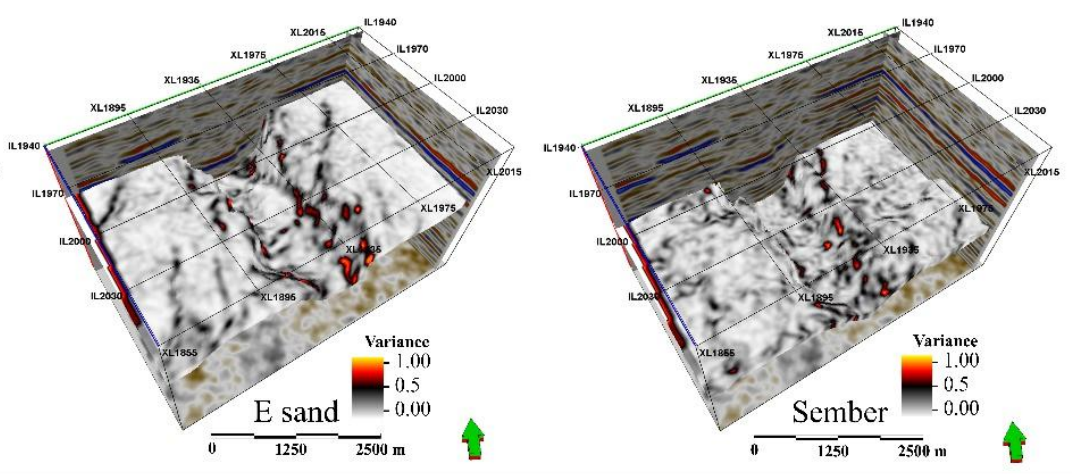

Figure 16. (a) 3D Variance edge attribute volume; (b) 2D extracted variance cross-sections; (c) 3D variance horizons slices of $G$ sand interval, E sand interval, and the Sembar Formation showing discontinuities (e.g., fault traces with better resolution of discontinuity). The darkest regions (e.g., values between 0.8 to 1 ) on $2 \mathrm{D}$ variance cross-sections and $3 \mathrm{D}$ horizon slices which make up vertical strips, represent high reflectivity sediments.

\subsubsection{Sweetness Attribute}

Figure 17 shows the computed sweetness attribute from the $3 \mathrm{D}$ seismic volume, corresponding cross-sections (e.g., A-A', B-B', C-C', D-D', E-E', and F-F'), and sweetness horizons slices, respectively. The sweetness anomalies on 2D cross-sections and horizon slices ranges from 0 (blue) to 6000 (yellow). The high sweetness anomalies (at -1900 to $-2300 \mathrm{~ms}$ ) on 2D sweetness cross-sections (Figure 17b) and 3D horizon slices (e.g., G sand and $\mathrm{E}$ sand intervals) (Figure 17c) may be contributed to the high amplitude and low frequency. In contrast, the low sweetness anomalies (at -2300 to $-2500 \mathrm{~ms}$ ) on 2D sweetness cross-sections and the SW-NE parts on 3D horizon slices (e.g., the Sembar Formation) due to the seismic cross-sections' low amplitude and high frequency. The high amplitude (high acoustic impedance as opposed to shale) and low frequency anomalies on both 2D sweetness cross-sections and 3D sweetness horizons slices represent cleaner and payable sand zones in Figures $17 b, c$, respectively. These sweet spots suggest the occurrence of the high proportion of porous sand and seem to be the potential for producing gas at the SW and NE parts within G and E sand reservoir intervals (Figure 17c). In contrast, areas with low amplitude and high frequency anomalies within the -2100 to $-2300 \mathrm{~ms}$ on 2D sweetness cross-sections non-reservoir window (e.g., the Sembar Formation) are susceptible to shale prone or these sands interbedded with shales. Although the sweetness attribute effectively distinguishes sand bodies from shale, it dues to the high acoustic impedance contrast between sand and shale. One of the sweetness attribute limitations is that it is less effective when low acoustic impedance contrast between shale and sandstone units. In most cases, the shale 
interval is characterized by low amplitude (low acoustic impedance contrast) and high frequency, indicating high sweetness [20,40].
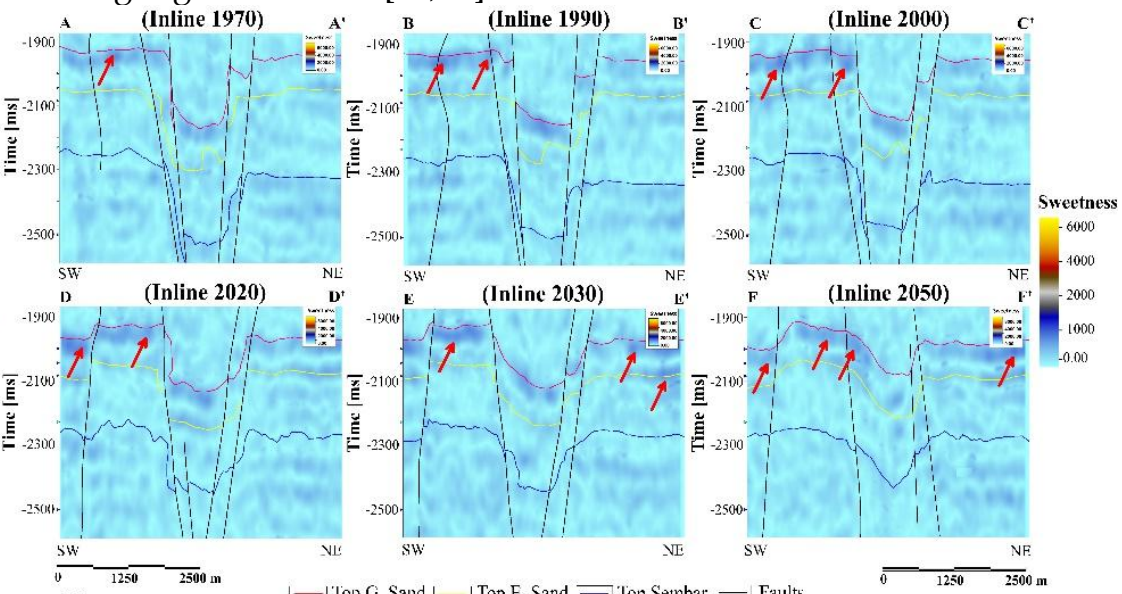

(a)

(b)
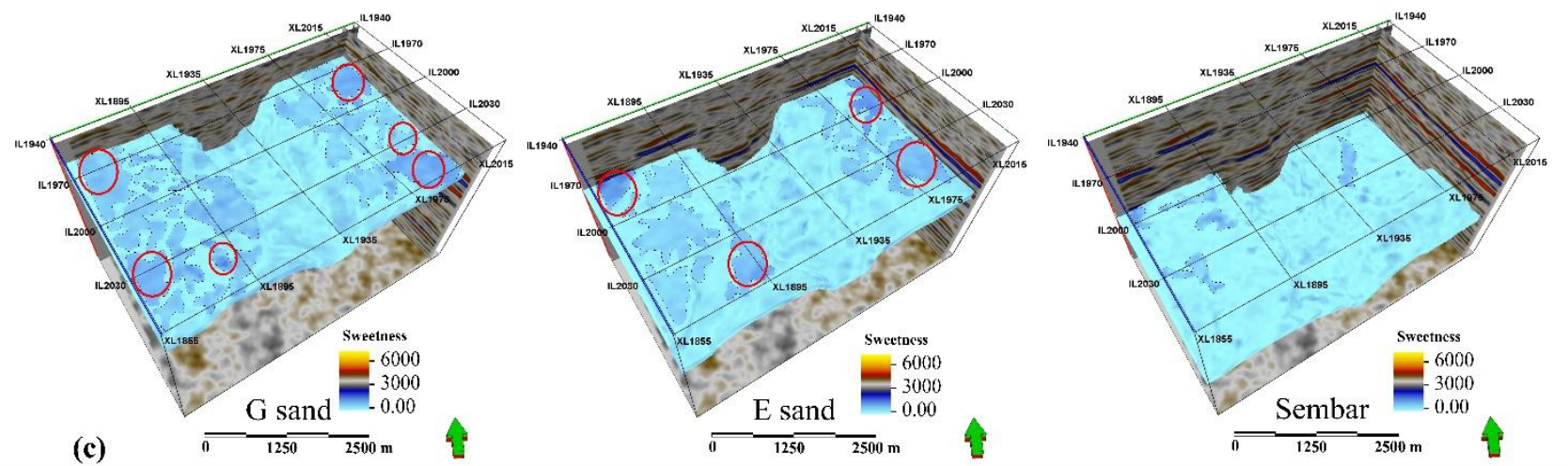

Figure 17. (a) 3D sweetness attribute volume; (b) 2D extracted sweetness cross-sections; (c) 3D sweetness horizons slices of $G$ sand interval, E sand interval, and Sembar Formation. The high amplitude and low-frequency content represent cleaner and payable sand (gas-charged bearing sand). The low amplitude and high-frequency content are susceptible to shale prone or these sands interbedded with shales.

\subsubsection{RMS amplitude Attribute}

The RMS amplitude attribute is a good resemble of acoustic impedance contrasts, providing good reflection strength. It measures the highest amplitude values from the seismic dataset and displays hydrocarbon-prone areas. The higher the acoustic impedance values, the higher the RMS amplitude and vice versa. Figure 18 shows the results of RMS amplitude estimated from the $3 \mathrm{D}$ seismic volume, appropriate $2 \mathrm{D}$ cross-section (e.g., A-A', B-B', C- $\mathrm{C}^{\prime}, \mathrm{D}-\mathrm{D}^{\prime}, \mathrm{E}-\mathrm{E}^{\prime}$, and $\mathrm{F}-\mathrm{F}^{\prime}$ ), and 3D horizon slices (e.g., G sand interval, E sand interval, and the Sembar Formation). The extracted 2D RMS amplitude cross-sections anomalies range from 0 to $4000 \mathrm{~ms}$ (Figure 18b). These amplitude variations suggest variability in lithology. The moderate to high amplitude anomalies within -1950 to $-2150 \mathrm{~ms}$ are often associated with channel sand bodies, high porosity (porous sands), and sand-rich sand shoreward facies, especially gas saturated sand zones. The gas saturated sand zones (e.g., -1900 to $-2100 \mathrm{~ms}$ ) have high reflectivity indicating high porosity within $\mathrm{G}$ and $\mathrm{E}$ sand intervals. In comparison, low amplitudes anomalies at -2150 to $-2500 \mathrm{~ms}$ may indicate that these zones contain sandy shale unfavorable zones for gas potential. The unfavorable zones for gas potential are mainly the zone of the Cretaceous organic-rich shales of the Sembar Formation (Figure 18b).

In order to effectively evaluate the structure influence on depositional facies, RMS amplitude attribute were computed at G sand interval, E sand interval, and the Sembar horizons slices (Figure 18c). These horizons slices reveal the lateral spatial distribution of 
facies due to the amplitude anomaly of acoustic impedance contrast caused by differences in lithological variation. The lateral spatial distribution of facies represents that the faults and fractures significantly decrease the reservoir quality ( $G$ sand and $E$ sand intervals). These reservoir intervals consist of channel sand bodies, porous sands, sand-rich sand shoreward facies (especially gas saturated zones). However, the Sembar Formation consists of sandy shale, and shale (unfavorable zones for gas potential). The high gas saturated zones lie at the SW and NE parts of the G and E sand intervals. These sand-rich gas saturated zones can be considered for future gas exploration in the study

(a)

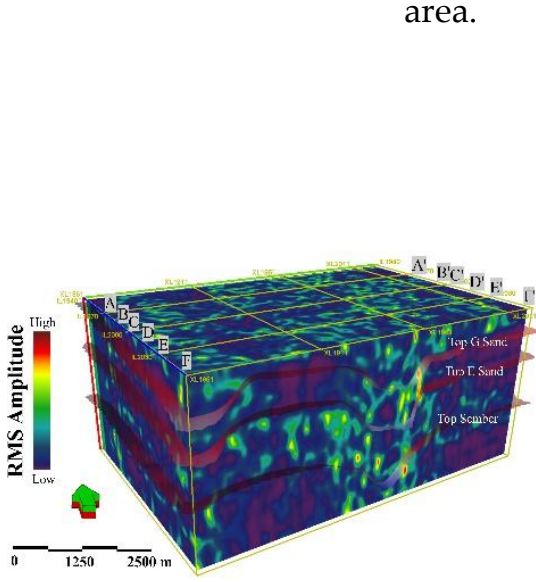
area.

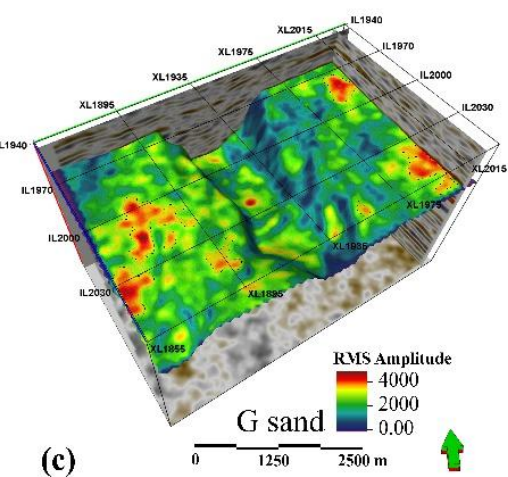

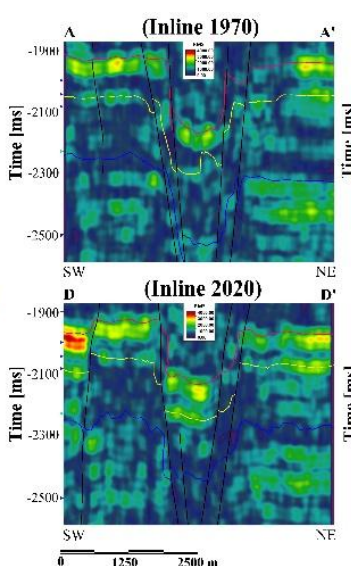

(b)

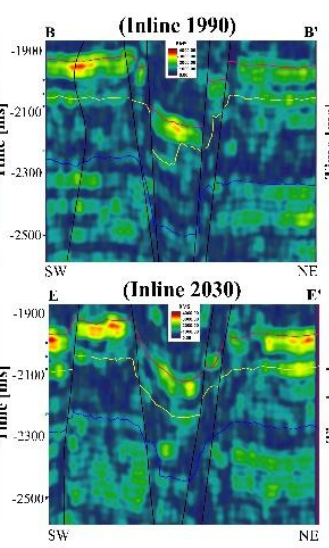

TopE Sand $=$ TopScmbar -1 Faults - Bright Spots

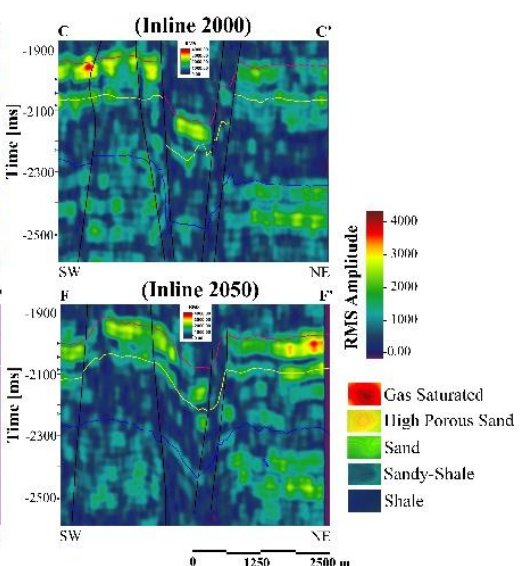

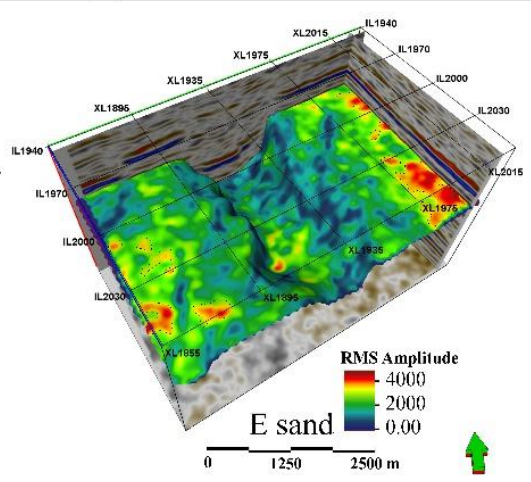

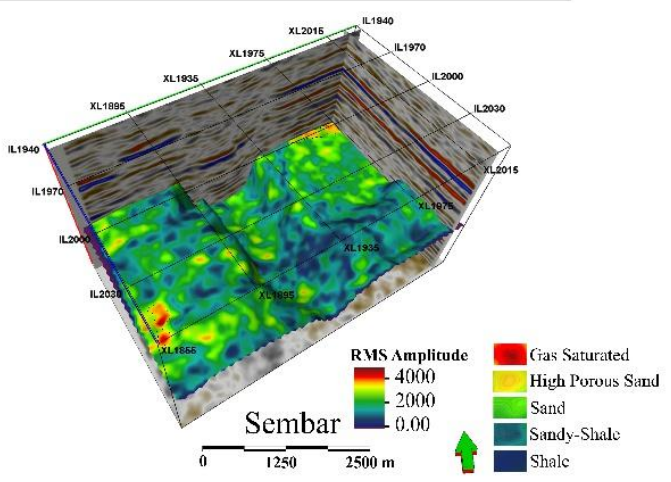

662

663

664

665

666

667

668

669

670

671

672

673

674

675

676

677

678

679

680

Figure 18. (a) 3D RMS amplitude volume; (b) corresponding 2D extracted cross-sections; (c) And 3D RMS amplitude horizons slices of G sand, E sand, and the Sembar Formation. These show highly porous lithology, low porous lithology, and fault traces corresponding discontinuity. The high RMS amplitude values between 2500 to 4000 (ms) represent sand-rich shoreward facies, which can be interpreted as gas saturated sand zones. The relatively low amplitudes values between 0 to 2000 (ms) indicate the zones of sandy-shale, shale, and pro-delta facies (unfavorable for gas potential).

\subsection{Petrophysical Modeling}

After determining the structural and stratigraphic configuration of the interpreted reservoir horizons, suites of wireline logs were used to evaluate the petrophysical characteristics of two hydrocarbon-bearing sand intervals (i.e., G and E sand). The petrophysical modeling unveils the reservoir traits and augments an intuition of hydrocarbon-bearing zones. The derived average petrophysical properties such as volume of $V_{\text {shale, }} \emptyset_{\text {avg, }} \emptyset_{\text {eff, }}$ and $S_{W}$ of the $G$ sand interval in both wells are $36.11 \%, 12.5 \%$, $7.5 \%$, and $45 \%$, respectively (Table 6). Similarly, the derived average petrophysical properties for the E sand interval in both wells are $30.5 \%, 17.4 \%, 12.2 \%$, and $33.2 \%$, respectively (Table 7). The graphical representation of these properties is presented in Figures 19 and 20, respectively. The overall description of the G and E sand reservoir intervals depends on these petrophysical properties, which may significantly influence 
decision-making in all phases of planning and execution of hydrocarbon activities in the Kadanwari field, MIIB, Pakistan.

Table 6. Petrophysical properties of the Cretaceous age G sand interval in Kadanwari-10 and Kadanwari-11 wells.

\begin{tabular}{cccccc}
\hline Well No. & Intervals & $\begin{array}{c}\text { Volume of shale } \\
\left(\mathbf{V}_{\text {shale }}\right)\end{array}$ & $\begin{array}{c}\text { Effective Porosity } \\
\left(\emptyset_{\text {eff }}\right)\end{array}$ & $\begin{array}{c}\text { Average Porosity } \\
\left(\boldsymbol{\emptyset}_{\text {avg }}\right)\end{array}$ & $\begin{array}{c}\text { Water Saturation } \\
\left(\mathbf{S}_{\mathbf{w}}\right) \mathbf{\%}\end{array}$ \\
\hline Kadanwari-10 & G sand interval & 36.11 & 7.8 & 12.2 & 45.4 \\
Kadanwari-11 & G sand interval & 36.11 & 8 & 12.56 & 45.4 \\
\hline
\end{tabular}

Table 7. Petrophysical properties of the Cretaceous age E sand interval in Kadanwari-10 and Kadanwari-11 wells.

\begin{tabular}{cccccc}
\hline Well No. & Intervals & $\begin{array}{c}\text { Volume of shale } \\
\left(\mathbf{V}_{\text {shale }}\right) \boldsymbol{\%}\end{array}$ & $\begin{array}{c}\text { Effective Porosity } \\
\left(\emptyset_{\text {eff }}\right) \boldsymbol{\%}\end{array}$ & $\begin{array}{c}\text { Average Porosity } \\
\left(\boldsymbol{\emptyset}_{\text {avg }}\right) \boldsymbol{\%}\end{array}$ & $\begin{array}{c}\text { Water Saturation } \\
\left(\mathbf{S}_{\mathbf{w}}\right) \boldsymbol{\%}\end{array}$ \\
\hline Kadanwari-10 & E sand interval & 27.02 & 13.2 & 18.1 & 30.09 \\
Kadanwari-11 & E sand interval & 34.05 & 11.3 & 16.7 & 36.42 \\
\hline
\end{tabular}

The GR log response is sensitive to detecting radioactive emissions that are predominantly concentrated in clay minerals of shale and clean sand (feldspar rich) [50]. The GR response in track 1 in each understudy wells confirms the reservoir lithology as sandstone (Figure 19 and 20). Lithology is the decisive factor of reservoir capacity and development ability of formation. Figure 19 represents the relationship between $\mathrm{V}_{\text {shale }}$ and sand content (track 1), $\emptyset_{\text {avg }}$ distribution (track 2), $\emptyset_{\text {eff }}$ distribution (track 3 ), and the relation of $S_{\mathrm{W}}$ and $S_{\mathrm{hc}}$ (track 4) at the G sand interval in Kadanwari-10 and 11 wells, respectively. Similarly, Figure 20 represents the relationship of $V_{\text {shale }}$ and sand content (track 1), $\emptyset_{\text {avg }}$ distribution (track 2), $\emptyset_{\text {eff }}$ distribution (track 3), and the relation of $S_{W}$ and $S_{\mathrm{hc}}($ track 4$)$ at the E sand interval in Kadanwari-10 and 11 wells, respectively.

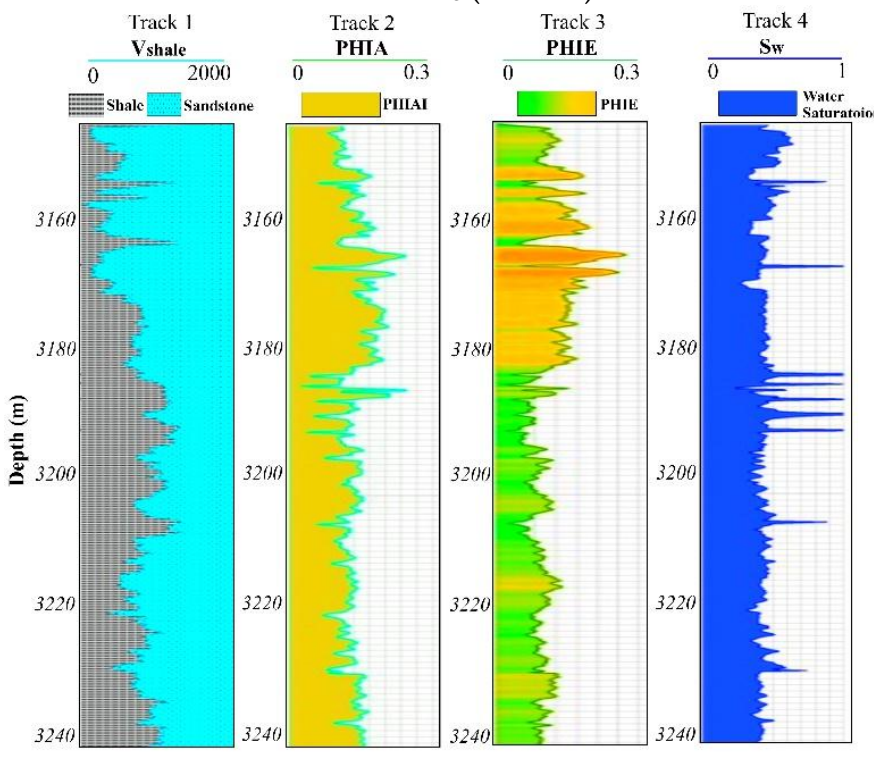

(a)
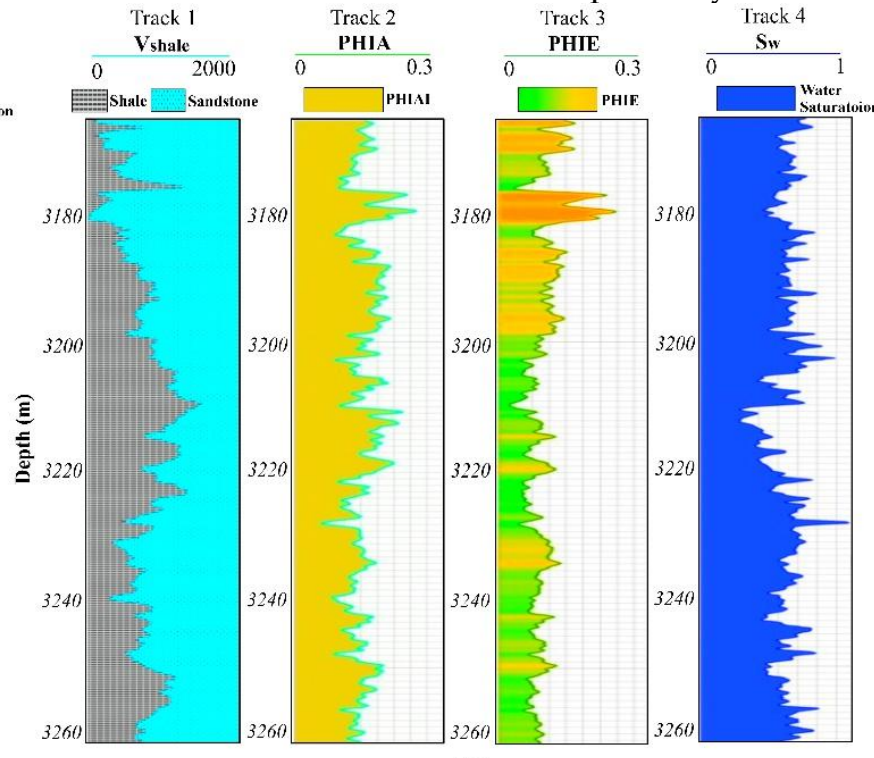

(b)

Figure 19. Relationship between the $V_{\text {shale }}$ and volume of sand (track 1), distribution of $\emptyset_{\text {avg }}$ (track 2 ), distribution of $\emptyset_{\text {eff }}$ (track 3), and the relationship of $S_{\mathrm{W}}$ and $S_{\mathrm{hc}}$ with respect to the depth at $G$ sand interval in (a) Kadanwari 10; (b) and Kadanwari-11 wells. 

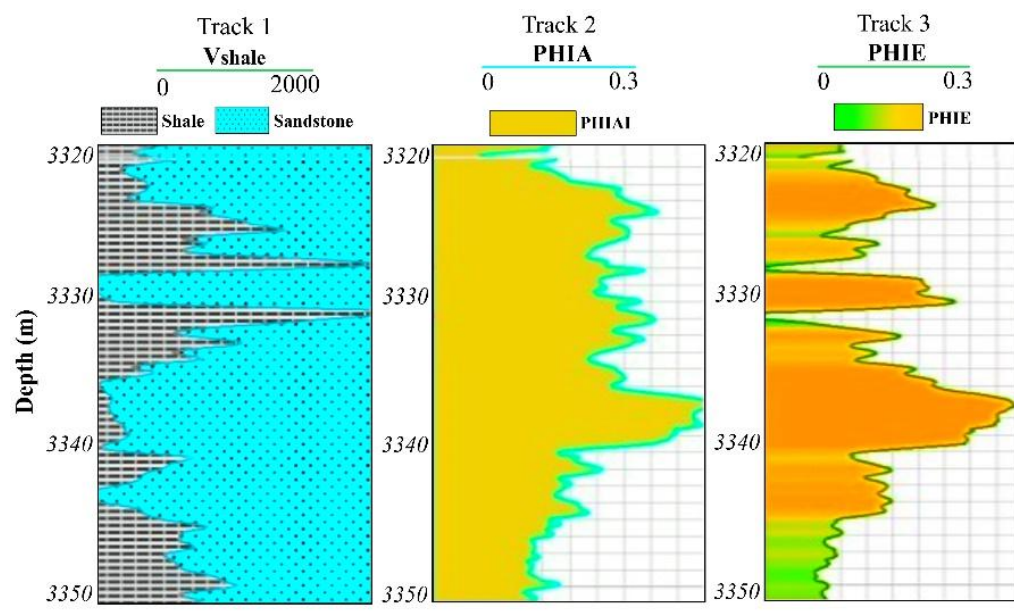

(a)
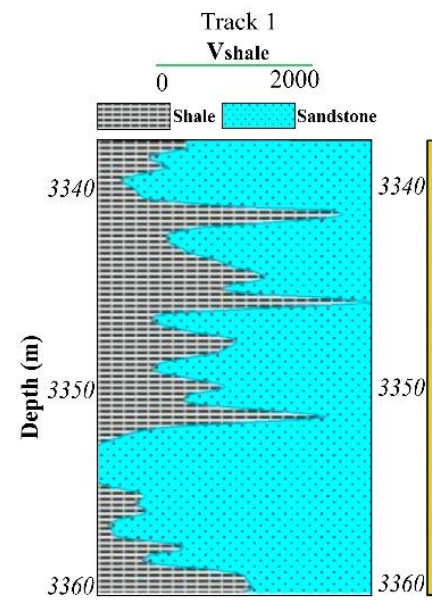
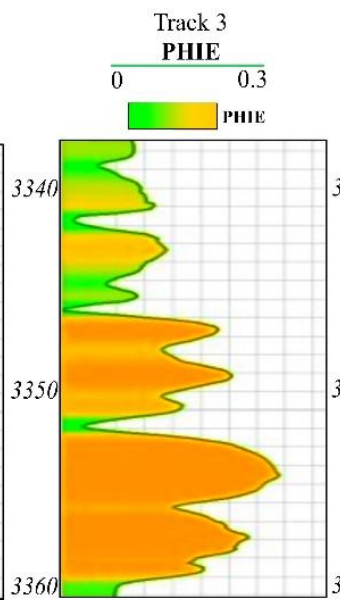

(b)
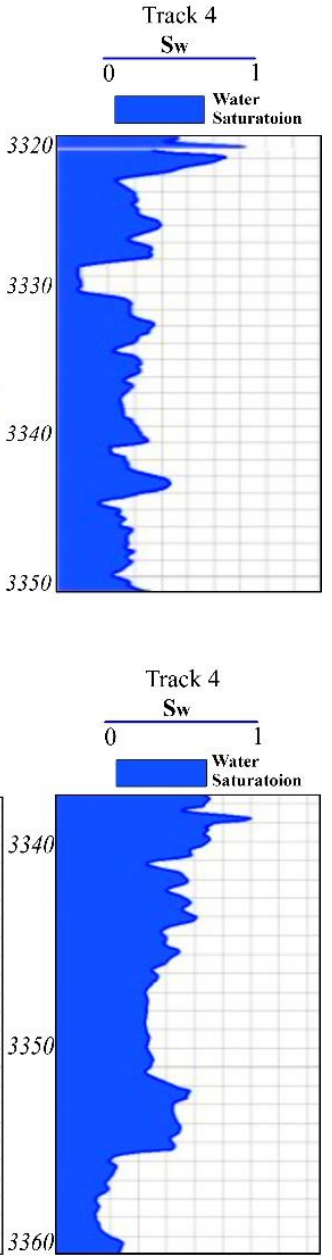

Figure 20. Relationship between the $V_{\text {shale }}$ and volume of sand (track 1), distribution of $\emptyset_{\text {avg }}$ (track 2 ), distribution of $\emptyset_{\text {eff }}$ (track 3), and the relationship of $S_{W}$ and $S_{h c}$ with respect to the depth at $E$ sand interval in (a) Kadanwari 10; (b) and Kadanwari-11 wells.

\subsubsection{Hydrocarbon Potential and Prospect}

The $S_{W}$ values calculated for $G$ sand and $E$ sand intervals were used to determine the $S_{\mathrm{hc}}$. The calculated values of the $S_{\mathrm{hc}}$ form the basis of future production forecasts and the determination of the economic viability of the discovered reservoir. Therefore, high accuracy is needed to determine $S_{W}$ as it calculates the $S_{h c}$ estimated reserves. The graphical representation of the Shc at the G and E sand reservoir intervals are presented in track 4 in Figures 19 and 20, respectively. The petrophysical modeling results show that these intervals have good $S_{h c}$ as the SW is fewer than $60 \%$ (Table 8). The sweetness and RMS amplitude attributes significantly identified high amplitude and low frequency seismic anomalies, which are often associated with high porosity (porous sands), sand-rich sand shoreward facies, bright spots, and especially gas saturated sand zones. The comparison between $\mathrm{G}$ and $\mathrm{E}$ sand intervals petrophysical properties shows that $\mathrm{E}$ sand interval has good $\emptyset_{\text {eff }}$ and $S_{\mathrm{hc}}$ and shows an apparent gas effect revealed by the cross-overs of DT and NPHI logs curves (Figure 8). Therefore, it can be considered as an economically viable reservoir interval. The $S_{\mathrm{hc}}$ percentage of the $\mathrm{E}$ sand interval is satisfactory for exploration purposes.

The annual report (2010-2011) of petroleum exploration and production activities in Pakistan analyzed the reserves of the Kadanwari field (Table 9) [7]. The Kadanwari field shows a significant amount of original recoverable gas reserves, i.e., 1110 billion cubic feet (Bcf) equivalent to 190 Million Barrels of Oil Equivalent (Mboe), respectively. Out of 
these original recoverable gas reserves, 420 (Bcf) have been extracted from the Kadanwari field. As of June 30, 2011, the balance recoverable gas reserves were $690 \mathrm{Bcf}$, equivalent to 110 Mboe for the Kadanwari field. Collective original recoverable reserves of 280 Mboe of the Kadanwari field are now limited to 129 Mboe [7]. Thus, a significant amount of hydrocarbon reserves is present in the Kadanwari field. The increased gas reserves in the Kadanwari field compared to other fields (such as the Miano field) may be attributed to the complex structural configuration (e.g., negative flower structure of fault system), reservoir compartmentalization, and up-dip migration of the hydrocarbons to the reservoir intervals (e.g., G and E sand).

Table 8. Depth range, thickness, and $S_{\mathrm{hc}}(\%)$ of the Cretaceous age $\mathrm{G}$ and $\mathrm{E}$ sand intervals in Kadanwari-10 and 11 wells.

\begin{tabular}{ccccc}
\hline Well No. & Intervals & Depth Range $(\mathbf{m})$ & Thickness $(\mathbf{m})$ & Hydrocarbon Saturation $\left(\mathbf{S}_{\text {hc }}\right)$ \% \\
\hline \multirow{2}{*}{ Kadanwari-10 } & G sand interval & $3145-3240$ & 95 & 54.6 \\
& E sand interval & $3320-3350$ & 30 & 70.01 \\
\hline \multirow{2}{*}{ Kadanwari-11 } & G sand interval & $3167-3260$ & 93 & 55.02 \\
& E sand interval & $3337-3360$ & 23 & 63.58 \\
\hline
\end{tabular}

Table 9. The Gas reserves of Kadanwari and Miano field until June 30, 2011.

\begin{tabular}{cccc}
\hline Fields & Original recoverable & Cumulative production & Balance recoverable \\
\hline Kadanwari & $1110 \mathrm{BCF}$ & $420 \mathrm{BCF}$ & $690 \mathrm{BCF}$ \\
Miano & $552 \mathrm{BCF}$ & $438 \mathrm{BCF}$ & $114 \mathrm{BCF}$ \\
\hline
\end{tabular}

\section{Discussion}

Knowledge of the structural and petrophysical characteristics is essential to reduce the uncertainties associated with the reservoir description. 3D seismic data were critically analyzed to understand the 3D faults system's formation mechanisms and spatial distribution. The detailed analysis of FSMs reveals that the reflectors appear irregular with faulted structural highs bounded by normal faults trending on NW to SE directions (Figure 11). The formation mechanism of FSMs showed that these faults formed as a result of the tectonic extension during the Cretaceous time. The geometric tendency of the extension-related normal FSMs is essential because it created channels for hydrocarbon migration in the vertical direction. The hydrocarbon enrichment in the $\mathrm{G}$ and $\mathrm{E}$ sand reservoir intervals was positively related to the complexity of the internal structure of these normal FSMs. The concentration and dominance of the faults are more intensive towards the central part of the seismic volume, where the faults are closely spaced. Other results from seismic sections interpreted in the study area, published by [7], showed similar structural patterns. According to [7], most faults are dipping towards the southwest with an average throw to the order of about $50 \mathrm{~m}$ and a maximum throw of $113 \mathrm{~m}$ in the Kadanwari area. Wrench or strike-slip faults are absent except for a probable one wrench fault (F3) to the south in the Kadanwari field (Figure 11c). Based on this, the possibility of strike-slip deformation may also be interpreted.

Furthermore, the detailed structural analysis of the 3D structural models and appropriate 2D cross-sections in Figure 15 reveals that the geological structural complexity is a consequence of different tectonic phases of deformation (compressional regimes of the surrounding plate boundary). The most structural event affecting the Kadanwari subsurface geological structure is the late Paleocene wrenching [48]. However, the final tectonic event that significantly influenced the Kadanwari area is the late Tertiary to Quaternary inversion of the Jacobabad-Khairpur High. The presence of the normal faults in NW to SE dipping directions are formed in pairs with parallel strike lines serves as evidence that they were developed due to the rifting of the Indian Plate. 
The fault plane profiles show the hanging wall and footwall cutoffs. These profiles are a fundamental tool for prospect assessment and considering the first step in understanding seal behavior because they show what is being juxtaposed across the fault. The normal faulted inversion-related horsts, half-graben, and graben structures show how the sedimentary layer's structural features were contributed to the formation of traps and conduit mechanisms (Figure 15c). [45] and [7] also stressed that the Kadanwari field is structurally essential due to the presence of fault-bounded structures, which may be considered as potential prospects. Due to the exact kinematic mechanisms described by the sequential deformation within the Kadanwari field, the structural deformation of each horizon is equal in orientation and deformation (Figure 15). However, the E sand interval seems to be more deformed than the G sand interval and the Sembar Formation. In future work, the generated 3D structural models and properties can be essential input databases for subsequent 3D facies and petrophysical modeling based on well logs upscaling. The subsurface structure complexity results obtained by 3D SM are in good agreement with the regional studies conducted by $[7,48,49]$.

According to our study, the successful application of variance edge, sweetness, and RMS amplitude attributes dramatically improves structural interpretation, visualization to 3D seismic data, distinguishing sand facies from shale, and evaluating direct hydrocarbon indicators (DHIs). The zones of interest are correlated with well log data, with the observed bright spots revealing possible hydrocarbon accumulation. The results of these seismic attribute analyses can significantly reduce the risk of hydrocarbon exploration and development in the Kadanwari field, MIB. The RMS amplitude attribute shows medium to high amplitude anomalies located in the SW and $\mathrm{NE}$ of the $\mathrm{G}$ and $\mathrm{E}$ sand horizon slices. These high amplitude anomalies are often associated with high porosity (porous sands), sand-rich sand shoreward facies, bright spots, and especially gas saturated sand zones (Figure 18c). In comparison, the low amplitude anomalies indicate that these zones contain sandy shale, pro-delta, or abyssal-plain facies, which are unfavorable zones for gas potential (Figure 18c). In the 3D SM, we evaluated that the geometrical trend of the extension related normal faults created an essential pathway for up-dip migration of the hydrocarbons from the source rock (the Sembar formation) towards the $G$ and $E$ sand reservoir intervals, resulting in hydrocarbon accumulation. These statements are validated here, as the moderate to high RMS amplitude anomalies are often associated with gas saturated sand zones. The hydrocarbon prospects have high reflectivity indicating high porosity, which can be seen on both the sweetness (Figure 17b) and RMS amplitude (Figure 18b) attributes within G and E sand intervals (e.g., -1900 to $-2100 \mathrm{~ms}$ ). In addition, the RMS amplitude attribute is advantageous compared with the sweetness attribute because the RMS amplitude attribute has a higher resolution in depicting the porous zones and DHIs.

In the petrophysical modeling, the evaluated low values of $V_{\text {shale }}$ content in Kadanwari 10 and 11 wells depict the cleanliness of the sandstone, which are presented in track 1 in Figures 19 and 20, respectively. Accordingly, shale and sandstone facies were separated by a $40 \%$ cutoff value in the targeted reservoir intervals, i.e., $\mathrm{G}$ and $\mathrm{E}$ sand. The $V_{\text {shale }}$ content in the $G$ and $E$ sand intervals are influenced by clay minerals which attempt to reduce the $\emptyset_{\text {avg }}$ and $\emptyset_{\text {eff. }}$ The high values of $\emptyset_{\text {eff }}$ in track 3 in Figures 19 and 20 refer to better volume estimation and thus theoretically a good reservoir and vice versa. These high values of $\emptyset_{\text {eff }}$ indicate the amount of connected pore spaces in the reservoir intervals [50]. The $\mathrm{G}$ and $\mathrm{E}$ sand reservoir intervals properties from the current petrophysical modeling are in good agreement with the regional study conducted by $[42,50,65]$.

\section{Conclusions}

We have introduced a novel methodology 3D structural modeling (3D SM) and joint geophysical characterization (JGC), that comprises seismic interpretation-aided 3D 
structural modeling, seismic attributes, and petrophysical modeling for reservoir characterization in the Kadanwari field, Middle Indus Basin (MIB), Pakistan. The insight derived from this integrated study is of interest to understanding the 3D stratigraphic architecture, lateral and horizontal extent of reservoir horizons, fault geometry and orientation, spatial facies, and properties, thereby identifying prospects and lessening hydrocarbon exploration risks. Our main findings are:

(1) 3D structural models and 2D structural cross-sections depict complex structural mechanics controlled by NW-SE dipping normal faults system in the early Cretaceous stratigraphic sequence. The identified features include horsts, half-graben, and graben structures. The spatial distribution of the fault system was identified by 3D dip angle models, steroenet, rose diagram, and histogram shows that the overall pattern of the interpreted faults system can be regarded as a negative flower structure. The negative flower structure concludes the combined effects of extensional and strike-slip motion in the study area. In general, the horsts, half-graben and graben and faults geometrically controlled reservoir ( $G$ and $E$ sand intervals) geomorphology, up-dip hydrocarbon migration, development of the local strata, distribution of facies and properties, and internal structural deformation.

(2) The variance edge attribute enhanced the geometric distribution of the faults within the seismic data volume. The sweetness attribute distinguished the sand facies from shale, as the high amplitude and loss in frequency content represents cleaner and payable sand zones. In contrast, areas with low amplitude and high frequency anomalies are susceptible to shale prone. The RMS amplitude and sweetness attribute results highlighted the hydrocarbon zones. The relatively high RMS amplitude attribute values are usually connected with lithological changes, sand-rich shoreward facies, bright spots, and especially gas saturated sand zones. In comparison, low amplitudes anomalies indicate the zones of sandy-shale, shale, and pro-delta facies

(3) The petrophysical modeling reveals important parameters for $G$ and $E$ sand reservoir intervals. The calculated $\emptyset_{\text {avg }}$ from the Sonic-Raymer (SR) porosity model, RHOB log, and NPHI log show that G and E sand reservoir intervals have good porosities. Moreover, E sand interval has good $\emptyset_{\text {eff }}$ and $S_{\text {hc }}$ and shows a clear indication of gas effect verified by the cross-overs of density and neutron log curves; therefore, it can be considered an economically viable reservoir interval for future hydrocarbon production.

Author Contributions: Conceptualization, U.K. and B.Z.; methodology, U.K. and J.D.; software, U.K.; validation, B.Z., J.D. and M.K.; formal analysis, S.A.; investigation, I.A.; data curation, S.H.; writing-original draft preparation, U.K. and Z.J.; writing-review and editing, B.Z.; funding acquisition, B.Z. All authors have read and agreed to the published version of the manuscript.

Funding: This study was supported by grants from the National Natural Science Foundation of China (Grant No. 42072326 and 41772348) and the National Key Research and Development Program of China (Grant No. 2019YFC1805905).

Acknowledgments: The authors would like to thank the Landmark Resources (LMKR) and the Directorate General of Petroleum Concessions (DGPC), Pakistan for providing the dataset. Many thanks to Umar Ashraf (Yunnan University, China) for revising the final version of this manuscript.

Conflicts of Interest: The authors declare no conflict of interest. 


\section{8}

869

\section{References}

1. Qadri, S.T.; Islam, M.A.; Shalaby, M.R.; Ali, S.H. Integration of 1D and 3D modeling schemes to establish the Farewell Formation as a self-sourced reservoir in Kupe Field, Taranaki Basin, New Zealand. Frontiers of Earth Science 2020, 1-18.

2. Thota, S.T.; Islam, M.A.; Shalaby, M.R. A 3D geological model of a structurally complex relationships of sedimentary Facies and Petrophysical Parameters for the late Miocene Mount Messenger Formation in the Kaimiro-Ngatoro field, Taranaki Basin, New Zealand. Journal of Petroleum Exploration and Production Technology 2021, 1-36.

3. Masters, C.D.; Root, D.H.; Attanasi, E.D.; Tedeschi, M.; Singh, S.; du Plessis, M.; Wong, S.; Redford, D.; Wightman, D.; MacGillivray, J. World resources of crude oil and natural gas. Energy Exploration \& Exploitation 1991, 354-374.

4. Khan, M.I.; Yasmin, T. Development of natural gas as a vehicular fuel in Pakistan: issues and prospects. Journal of natural gas science and engineering 2014, 17, 99-109.

5. Kosmacheva, A.; Fedorovich, M. Basin and petroleum system modeling in conjunction zone of the Alexander and Srednevasyugan anticlines and Ust-Tym depression, southeastern part of the West Siberian hydrocarbon province (Russia). Journal of Petroleum Exploration and Production 2021, 11, 539-548.

6. Ahmad, N.; Khan, S.; Al-Shuhail, A. Seismic Data Interpretation and Petrophysical Analysis of Kabirwala Area Tola (01) Well, Central Indus Basin, Pakistan. Applied Sciences 2021, 11, 2911.

7. Saif-Ur-Rehman, K.J.; Lin, D.; Ehsan, S.A.; Jadoon, I.A.; Idrees, M. Structural styles, hydrocarbon prospects, and potential of Miano and Kadanwari fields, Central Indus Basin, Pakistan. Arabian Journal of Geosciences 2020, 13, 1-13.

8. Khan, U.; Zhang, B.; Du, J.; Jiang, Z. 3D structural modeling integrated with seismic attribute and petrophysical evaluation for hydrocarbon prospecting at the Dhulian Oilfield, Pakistan. Frontiers of Earth Science 2021, 15, 649-675.

9. Bodunde, S.; Enikanselu, P. Integration of 3D-seismic and petrophysical analysis with rock physics analysis in the characterization of SOKAB field, Niger delta, Nigeria. Journal of Petroleum Exploration and Production Technology 2019, 9, 899-909.

10. Hossain, M.I.S.; Woobaidullah, A.; Rahman, M.J. Reservoir characterization and identification of new prospect in Srikail gas field using wireline and seismic data. Journal of Petroleum Exploration and Production Technology 2021, 1-15.

11. Kargarpour, M.A. Carbonate reservoir characterization: an integrated approach. Journal of Petroleum Exploration and Production Technology 2020, 10, 2655-2667.

12. Islam, M.A.; Yunsi, M.; Qadri, S.T.; Shalaby, M.R.; Haque, A.E. Three-dimensional structural and petrophysical modeling for reservoir characterization of the Mangahewa formation, Pohokura Gas-Condensate Field, Taranaki Basin, New Zealand. Natural Resources Research 2021, 30, 371-394.

13. Li, X.; Zhou, N.; Xie, X. Reservoir characteristics and three-dimensional architectural structure of a complex fault-block reservoir, beach area, China. Journal of Petroleum Exploration and Production Technology 2018, 8, 1535-1545.

14. Osinowo, O.O.; Ayorinde, J.O.; Nwankwo, C.P.; Ekeng, O.; Taiwo, O. Reservoir description and characterization of Eni field Offshore Niger Delta, southern Nigeria. Journal of Petroleum Exploration and Production Technology 2018, 8, 381-397.

15. Haque, A.E.; Islam, M.A.; Shalaby, M.R. Structural modeling of the Maui gas field, Taranaki basin, New Zealand. Petroleum Exploration and Development 2016, 43, 965-975.

16. Mutebi, S.; Sen, S.; Sserubiri, T.; Rudra, A.; Ganguli, S.S.; Radwan, A.E. Geological characterization of the Miocene-Pliocene succession in the Semliki Basin, Uganda: Implications for hydrocarbon exploration and drilling in the East African Rift System. Natural Resources Research 2021, 1-26.

17. Abdeen, M.M.; Ramadan, F.S.; Nabawy, B.S.; El Saadawy, O. Subsurface Structural Setting and Hydrocarbon Potentiality of the Komombo and Nuqra Basins, South Egypt: A Seismic and Petrophysical Integrated Study. Natural Resources Research 2021, 30, 3575-3603. 
18. Gao, D. Latest developments in seismic texture analysis for subsurface structure, facies, and reservoir characterization: A review. Geophysics 2011, 76, W1-W13.

19. Abuamarah, B.A.; Nabawy, B.S.; Shehata, A.M.; Kassem, O.M.; Ghrefat, H. Integrated geological and petrophysical characterization of oligocene deep marine unconventional poor to tight sandstone gas reservoir. Marine and Petroleum Geology 2019, 109, 868-885.

20. Ashraf, U.; Zhu, P.; Yasin, Q.; Anees, A.; Imraz, M.; Mangi, H.N.; Shakeel, S. Classification of reservoir facies using well log and 3D seismic attributes for prospect evaluation and field development: A case study of Sawan gas field, Pakistan. Journal of Petroleum Science and Engineering 2019, 175, 338-351.

21. Czoski, P. Geologic characterization of the Morrow B reservoir in Farnsworth Unit, TX using 3D VSP seismic, seismic attributes, and well logs. Geophysics 2014, 101.

22. Hussain, M.; Ahmed, N.; Chun, W.Y.; Khalid, P.; Mahmood, A.; Ahmad, S.R.; Rasool, U. Reservoir characterization of basal sand zone of lower Goru Formation by petrophysical studies of geophysical logs. Journal of the Geological Society of India 2017, 89, 331-338.

23. Radwan, A.E.; Rohais, S.; Chiarella, D. Combined stratigraphic-structural play characterization in hydrocarbon exploration: A case study of Middle Miocene sandstones, Gulf of Suez basin, Egypt. Journal of Asian Earth Sciences 2021, 104686.

24. Radwan, A.E. Modeling the depositional environment of the sandstone reservoir in the Middle Miocene Sidri Member, Badri Field, Gulf of Suez Basin, Egypt: Integration of gamma-ray log patterns and petrographic characteristics of lithology. Natural Resources Research 2021, 30, 431-449.

25. Houlding, S. 3D geoscience modeling: computer techniques for geological characterization; Springer Science \& Business Media: 2012.

26. Lajaunie, C.; Courrioux, G.; Manuel, L. Foliation fields and 3D cartography in geology: principles of a method based on potential interpolation. Mathematical Geology 1997, 29, 571-584.

27. Mallet, J.-L. Geomodeling; Oxford University Press: 2002.

28. $\mathrm{Wu}, \mathrm{Q}$; $\mathrm{Xu}, \mathrm{H}$.; Zou, X. An effective method for 3D geological modeling with multi-source data integration. Computers $\mathcal{E}$ geosciences 2005, 31, 35-43.

29. Zhang, B.-y.; Huang, A.; Lu, H.; Cheng, Q.-m. Geochemical field and its roles on the 3D prediction fo concealed ore-bodies [J]. Acta Petrologica Sinica 2018, 34, 352-362.

30. Wang, L.; Wu, X.; Zhang, B.; Li, X.; Huang, A.; Meng, F.; Dai, P. Recognition of significant surface soil geochemical anomalies via weighted $3 \mathrm{D}$ shortest-distance field of subsurface orebodies: a case study in the Hongtoushan copper mine, NE China. Natural Resources Research 2019, 28, 587-607.

31. Moore, G.F. 3 - D seismic interpretation. 2009.

32. Adelu, A.O.; Aderemi, A.; Akanji, A.O.; Sanuade, O.A.; Kaka, S.I.; Afolabi, O.; Olugbemiga, S.; Oke, R. Application of 3D static modeling for optimal reservoir characterization. Journal of African Earth Sciences 2019, 152, 184-196.

33. Ayodele, O.L.; Chatterjee, T.; Opuwari, M. Static reservoir modeling using stochastic method: a case study of the cretaceous sequence of Gamtoos Basin, Offshore, South Africa. Journal of Petroleum Exploration and Production Technology 2021, 11, 4185-4200.

34. Jung, A.; Aigner, T.; Palermo, D.; Nardon, S.; Pontiggia, M. A hierarchical database on carbonate geobodies and its application to reservoir modelling using multi-point statistics. In Proceedings of the 72nd EAGE Conference and Exhibition incorporating SPE EUROPEC 2010, 2010; pp. cp-161-00314.

35. Li, J.; Zhang, X.; Lu, B.; Ahmed, R.; Zhang, Q. Static Geological Modelling with Knowledge Driven Methodology. Energies 2019, 12, 3802.

36. Okoli, A.E.; Agbasi, O.E.; Lashin, A.A.; Sen, S. Static Reservoir Modeling of the Eocene Clastic Reservoirs in the Q-Field, Niger Delta, Nigeria. Natural Resources Research 2021, 30, 1411-1425. 
37. Ali, M.; Abdelhady, A.; Abdelmaksoud, A.; Darwish, M.; Essa, M.A. 3D static modeling and petrographic aspects of the Albian/Cenomanian Reservoir, Komombo Basin, Upper Egypt. Natural Resources Research 2020, 29, 1259-1281.

38. Manzi, M.S.; Cooper, G.R.; Malehmir, A.; Durrheim, R.J. Improved structural interpretation of legacy 3D seismic data from Karee platinum mine (South Africa) through the application of novel seismic attributes. Geophysical Prospecting 2020, 68, $145-163$.

39. Chopra, S.; Marfurt, K. Seismic Attributes-a promising aid for geologic prediction. CSEG Recorder 2006, 31, 110-120.

40. Azeem, T.; Yanchun, W.; Khalid, P.; Xueqing, L.; Yuan, F.; Lifang, C. An application of seismic attributes analysis for mapping of gas bearing sand zones in the sawan gas field, Pakistan. Acta Geodaetica et Geophysica 2016, 51, 723-744.

41. Naseer, M.T. Seismic attributes and quantitative stratigraphic simulation'application for imaging the thin-bedded incised valley stratigraphic traps of Cretaceous sedimentary fairway, Pakistan. Marine and Petroleum Geology 2021, 134, 105336.

42. Ali, M.; Khan, M.J.; Ali, M.; Iftikhar, S. Petrophysical analysis of well logs for reservoir evaluation: a case study of "Kadanwari" gas field, middle Indus basin, Pakistan. Arabian Journal of Geosciences 2019, 12, 1-12.

43. Raza, M.; Khan, F.; Khan, M.; Riaz, M.; Khan, U. Reservoir characterization of the B-interval of lower goru formation, miano 9 and 10, miano area, Lower Indus Basin, Pakistan. Environ Earth Sci Res J 2020, 7, 18-32.

44. Kadri, I. Petroleum geology of Pakistan, sedimentary basins and their evolution. Pakistan Petroleum Limited $1995,32$.

45. Ahmad, N.; Chaudhry, S. Kadanwari Gas Field, Pakistan: a disappointment turns into an attractive development opportunity. Petroleum Geoscience 2002, 8, 307-316.

46. Ahmad, N.; Fink, P.; Sturrock, S.; Mahmood, T.; Ibrahim, M. Sequence stratigraphy as predictive tool in lower goru fairway, lower and middle Indus platform, Pakistan. PAPG, ATC 2004, 85-104.

47. Munir, K.; Iqbal, M.A.; Farid, A.; Shabih, S.M. Mapping the productive sands of Lower Goru Formation by using seismic stratigraphy and rock physical studies in Sawan area, southern Pakistan: a case study. Journal of Petroleum Exploration and Production Technology 2011, 1, 33-42.

48. Ahmed, W.; Azeem, A.; Abid, M.F.; Rasheed, A.; Aziz, K. Mesozoic structural architecture of the middle Indus Basin, Pakistan-controls and implications. In Proceedings of the PAPG/SPE annual technical conference, Islamabad, Pakistan, 2013; pp. 1-13.

49. Saif-Ur-Rehman, K.J.; Mehmood, M.F.; Shafiq, Z.; Jadoon, I.A. Structural styles and petroleum potential of Miano block, central Indus Basin, Pakistan. International Journal of Geosciences 2016, 7, 1145.

50. Khan, M.J.; Khan, H.A. Petrophysical logs contribute in appraising productive sands of Lower Goru Formation, Kadanwari concession, Pakistan. Journal of Petroleum Exploration and Production Technology 2018, 8, 1089-1098.

51. Naseer, M.T. Imaging of Stratigraphic Pinch-Out Traps Within the Lower-Cretaceous Shaly-Sandstone System, Pakistan, Using 3D Quantitative Seismic Inverted Porosity-Velocity Modeling. Natural Resources Research 2021, 30, $4297-4327$.

52. Kazmi, A.; Jan, M. Geology and Tectonics of Pakistan Graphic Publishers. ISBN: 9698375007, 9789698375003 $1997,554$.

53. Ali, A.M.; Radwan, A.E.; El-Gawad, A.; Esam, A.; Abdel-Latief, A.-S.A. 3D Integrated Structural, Facies and Petrophysical Static Modeling Approach for Complex Sandstone Reservoirs: A Case Study from the Coniacian-Santonian Matulla Formation, July Oilfield, Gulf of Suez, Egypt. Natural Resources Research 2021, 1-29.

54. Faleide, T.S.; Braathen, A.; Lecomte, I.; Mulrooney, M.J.; Midtkandal, I.; Bugge, A.J.; Planke, S. Impacts of seismic resolution on fault interpretation: Insights from seismic modelling. Tectonophysics 2021, 816, 229008.

55. Kim, M.; Yu, J.; Kang, N.-K.; Kim, B.-Y. Improved Workflow for Fault Detection and Extraction Using Seismic Attributes and Orientation Clustering. Applied Sciences 2021, 11, 8734.

56. Khan, M.; Abdelmaksoud, A. Unfolding impacts of freaky tectonics on sedimentary sequences along passive margins: Pioneer findings from western Indian continental margin (Offshore Indus Basin). Marine and Petroleum Geology 2020, 119, 104499. 
992 57. Qadri, S.T.; Islam, M.A.; Shalaby, M.R. Three-dimensional petrophysical modelling and volumetric analysis to model the reservoir potential of the Kupe Field, Taranaki Basin, New Zealand. Natural Resources Research 2019, 28, 369-392.

58. Shakir, U.; Ali, A.; Hussain, M.; Azeem, T.; Bashir, L. Selection of Sensitive Post-Stack and Pre-Stack Seismic Inversion Attributes for Improved Characterization of Thin Gas-Bearing Sands. Pure and Applied Geophysics 2021, 1-28.

996 59. Taner, M.T.; Koehler, F.; Sheriff, R. Complex seismic trace analysis. Geophysics 1979, 44, 1041-1063.

997 60. Emujakporue, G.O.; Enyenihi, E.E. Identification of seismic attributes for hydrocarbon prospecting of Akos field, Niger Delta, $998 \quad$ Nigeria. SN Applied Sciences 2020, 2, 1-11.

999 61. Ahmad, M.N.; Rowell, P. Application of spectral decomposition and seismic attributes to understand the structure and distribution of sand reservoirs within Tertiary rift basins of the Gulf of Thailand. The Leading Edge 2012, 31, 630-634.

62. Iqbal, M.A.; Rezaee, R. Porosity and Water Saturation Estimation for Shale Reservoirs: An Example from Goldwyer Formation Shale, Canning Basin, Western Australia. Energies 2020, 13, 6294.

63. Dolan, P. Pakistan: a history of petroleum exploration and future potential. Geological Society, London, Special Publications 1990, 50, 503-524.

64. Rider, M. Gamma-ray log shape used as a facies indicator: critical analysis of an oversimplified methodology. Geological Society, London, Special Publications 1990, 48, 27-37.

65. Sam-Marcus, J.; Enaworu, E.; Rotimi, O.J.; Seteyeobot, I. A proposed solution to the determination of water saturation: using a modelled equation. Journal of Petroleum Exploration and Production Technology 2018, 8, 1009-1015. 